\title{
Projeto e construção de um Dinamômetro para medir o torque dinâmico de um eixo rotativo
}

\author{
Oscar de Bortoli Vieiria \\ 100589@upf.br \\ Universidade de Passo Fundo (UPF), \\ Passo Fundo, Rio grande do Sul, Brasil \\ Leandro Doró Tagliari \\ leandrotagliari@upf.br \\ Universidade de Passo Fundo (UPF), \\ Passo Fundo, Rio grande do Sul, Brasil \\ Guilherme Regner Nava \\ 142726@upf.b \\ Universidade de Passo Fundo (UPF) \\ Passo Fundo, Rio grande do Sul, Brasil \\ Cristian Bicigo \\ 127525@upf.b \\ Universidade de Passo Fundo (UPF), \\ Passo Fundo, Rio grande do Sul, Brasil \\ Leonardo Castilhos de Oliveira \\ 138283@upf.br \\ Universidade de Passo Fundo (UPF) \\ Passo Fundo, Rio grande do Sul, Brasil
}

\author{
RESUMO
}

Este trabalho consiste em desenvolver o projeto e a construção de um dinamômetro para ser acoplado no eixo árvore de um centro de usinagem vertical. O dinamômetro a ser desenvolvido deve ser capaz de monitorar parâmetros de processo, objetivando o mensuramento do torque dinâmico. Para o funcionamento do dinamômetro, uma deformação deve ser analisada. Neste caso, a deformação é dada por uma mola calibrada. Sua deformação e variações na velocidade de rotação serão captadas por sensores infravermelhos e, como utiliza um método sem contato na medição e transmissão, acaba tornando-se menos sensível a vibrações. Manter uma boa fixação e evitar vibrações, são fatores importantes dentro do projeto, então o estudo sobre rolamentos, ajustes e tolerâncias se faz necessário. Outro fator importante a ser considerado são os materiais específicos de cada componente, visando evitar excesso de peso e baixar o custo, sem comprometer a aquisição de dados. Com o respectivo projeto pretende-se suprir uma necessidade do laboratório de usinagem de medição de esforços, além do conhecimento técnico que será adquirido, tanto da parte mecânica como da parte eletrônica, durante seu desenvolvimento, aquisição e interpretação de informações. Obteve se como resultado um dispositivo barato, fabricado com materiais já existentes no laboratório e capaz de realizar satisfatoriamente o mensuramento do torque dinâmico de um eixo rotativo de uma determinada máquina.
\end{abstract}

PALAVRAS-CHAVE: Dinamômetros. Torque dinâmico. Torque rotativo. 


\section{INTRODUÇÃO}

A busca por aperfeiçoar os métodos de processo e fabricação exige cada vez mais estudo, pois o mercado em função de um mundo globalizado está tornandose cada vez mais competitivo.

Novos dispositivos estão sendo desenvolvidos ou aperfeiçoados para controlar melhor os parâmetros de fabricação, a fim de aproveitar melhor o tempo e mão de obra.

Uma característica comum em várias empresas são processos que acabam sendo mais custosos quando produzidos na própria empresa do que os mesmos terceirizados, o ideal é identificar o problema, mas para calcular esse custo são necessários dados que não são encontrados com facilidade.

Esse é o objetivo deste projeto, desenvolver um equipamento que forneça as informações adicionais sobre o processo.

A medição do torque de eixos em rotação foi analisada, tanto com os métodos convencionais como com soluções inovadoras. Isso possibilitou a leitura do torque de forma direta da deformação radial, e também por meio do ângulo de torção.

$O$ instrumento geralmente utilizado para quantificar esforços atuantes sobre um elemento mecânico é o dinamômetro, recomenda-se realizar a descrição de um modelo matemático a partir das deformações sofridas pelo material.

Posterior a isso usar os dados obtidos com medições diretas e com metrologia tradicional. Os dinamômetros são basicamente a medição de deformação de uma mola, de características conhecidas e previamente calibrada. (BORGES, 2015).

O foco deste trabalho é desenvolver o projeto e a construção de um dinamômetro capaz de medir o torque dinâmico em um eixo rotativo do centro de usinagem vertical V-400 do laboratório de usinagem da FEAR/UPF durante um processo de furação.

O aparelho foi projetado para ficar posicionado entre a broca utilizada na furação e o eixo árvore do centro de usinagem. O dinamômetro pode ter outras funções além do cálculo de custos de usinagem, pode também ser utilizado em estudos de métodos de usinagem, desenvolvimento de novas ferramentas de furação e futuros estudos.

Os dinamômetros encontrados no mercado além de um valor muito elevado, também possuem limitações que incapacitam a utilização do mesmo, como o modo de fixação e a forma de coleta de dados. Assim a alternativa foi construir um equipamento específico, com baixo custo, além de garantir que o mesmo desenvolva a função definida neste projeto.

\section{REVISÃO BIBLIOGRÁFICA}

Neste capítulo apresenta se a maneira de obter o torque a partir das deformações de torção, a análise do torque a partir dessas deformações, os métodos de medição de torque diretamente em eixos rotativos, bem como a metodologia de projeto utilizada. 


\section{OBTENÇÃO DO TORQUE A PARTIR DAS DEFORMAÇÕES DE TORÇÃO}

Os primeiros equipamentos criados para medir deformações eram essencialmente mecânicos, além de apresentar erros de medição e limitações. Posteriormente Charles Wheatstone em 1843, constatou com a evolução da eletroeletrônica que com a aplicação de uma tensão mecânica em um condutor elétrico sua resistência variava.

Depois Willian Thompson em 1856, conseguiu medir este efeito. Eduard. E Arthur Claude Ruge desenvolveram, depois de muito estudo, os primeiros extensômetros de resistência elétrica ou Strain Gages.

Graças a isso os extensômetros têm contribuído para estudos de análise de tensões e projeto mecânico. (GRANTE, 2004).

\section{Análise do Torque a partir das Deformações de Torção}

Analisando a deformação de um corpo de prova sob carregamento, de acordo com as deflexões medidas, define-se a tensão experimental. Em aplicações de engenharia é mais útil trabalhar com a grandeza tensão definida como força perpendicularmente distribuída em uma determinada área. (FIGLIOLA E BEASLEY, 2011).

O torque será definido como o resultado da ação de uma força sobre um corpo, de modo que essa força esteja aplicada perpendicularmente a uma distância $\rho$ do eixo longitudinal do sistema, havendo uma variação na velocidade angular do corpo pode então ser expresso matematicamente como:

$$
\vec{T}=\vec{\rho} \times \overrightarrow{\mathrm{F}}
$$

Este cálculo aplica-se para uma força resultante pontual. $\mathrm{O}$ torque também pode ser exercido por forças distribuídas sobre um objeto. Estas forças devem estar em um plano paralelo ao vetor $\rho$. Como ilustrado na Figura 1.

Figura 1: (a) torque de uma força sobre uma barra; (b) torque de uma distribuição uniforme de forças sobre uma barra; (c) torque de uma distribuição de forças sobre a secção reta de um cilindro

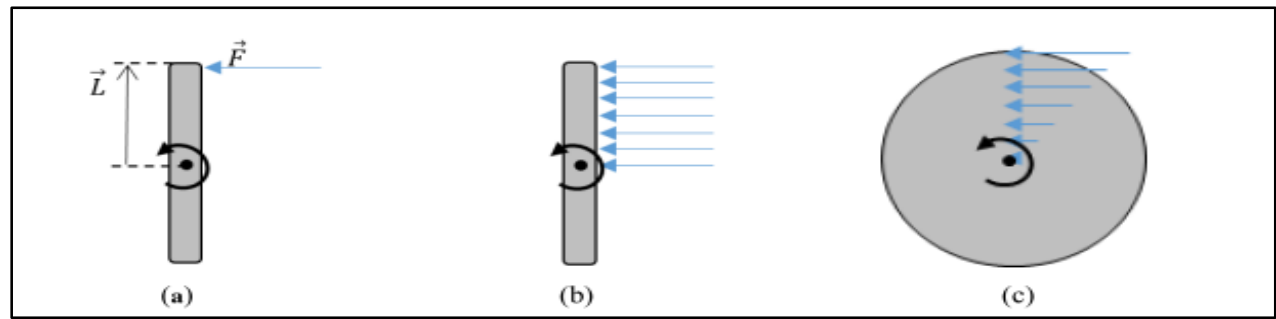

Fonte: Borges, Jacques (2015)

Seguindo o processo, o torque exercido por cada força contida no plano de atuação deve ser somado vetorialmente, assim obtendo o torque resultante na direção perpendicular ao plano. Para condição de forças distribuídas de forma uniforme será utilizado uma soma infinitesimal para a operação. Para o caso do cilindro teremos: (BORGES, 2015). 


$$
T=\int \rho d \mathrm{~F}=\int \rho \tau d A
$$

Sendo $\rho$ à distância até o centro do eixo e $\tau$ a tensão de cisalhamento. A distribuição das forças não pode ser considerada uniforme ao longo do eixo circular, pois é estaticamente impossível determinar como se dá a distribuição da tensão de cisalhamento. Para se chegar ao resultado do torque, deve-se obter a medição e deformação provocada por essa tensão cisalhante nas faces perpendiculares ao eixo do cilindro, devido às condições de equilíbrio, que requerem tensões iguais nas faces adjacentes ao longo do eixo (conforme Figura 2).

Figura 2 - Eixo circular sobre torção

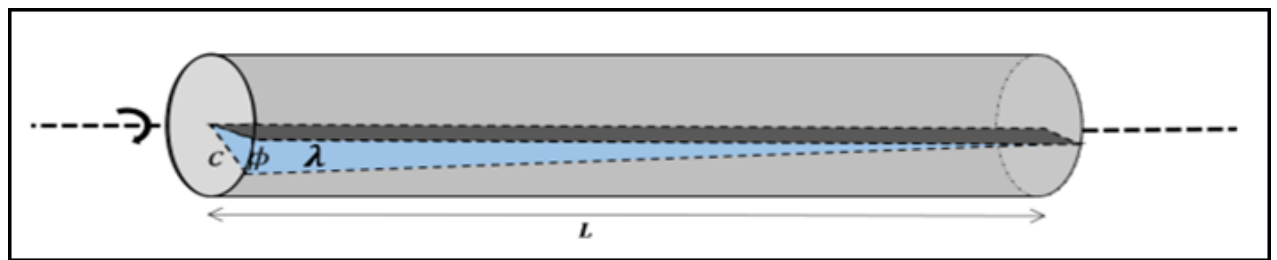

Fonte: Borges, Jacques (2015).

Classifica-se como c o raio do eixo circular, $\lambda$ como deformação radial, $L$ como comprimento do eixo e $\varnothing$ como ângulo da torção dentro da distância L. Já que o ângulo de torção do eixo é bastante pequeno, considera-se sen $(\varnothing) \cong \varnothing$, neste caso dado a equação:

$$
\lambda=\rho \frac{\phi}{L}
$$

De acordo com a lei de Hooke o $\rho$ assume o valor máximo quando seu valor for igual ao raio do eixo, portanto quando $\rho$ for igual a c será obtida a deformação radial máxima, dada por:

$$
\tau=\lambda \times G
$$

Sendo $G$ o módulo de elasticidade transversal do eixo. Utiliza-se dados anteriormente fornecidos, como a deformação máxima ocorre quando $\rho$ for igual a c, e as equações (3) e (4) obtemos:

$$
\frac{\tau}{\rho}=\frac{\tau_{\max }}{c} \rightarrow \tau=\frac{\rho}{c} \tau_{\max }
$$

A tensão de cisalhamento máxima, dada no cálculo, é a tensão de cisalhamento na superfície do material, que também é idêntica ao torque externo aplicado. Aplicando os resultados na equação (2) tem-se que:

$$
\begin{gathered}
T=\int \rho \tau d A \\
T=\int \rho\left(\frac{\rho}{c} \tau_{\max }\right) d A \\
T=\frac{\tau_{\max }}{c} \int \rho^{2} d A
\end{gathered}
$$




$$
T=\frac{\tau_{\max }}{c} J
$$

Sendo J o momento polar de inercia de área. Resolve-se a integral, considerando o eixo maciço, têm-se:

$$
J=\frac{1}{2} \pi c^{4}
$$

Aplicando os resultados das equações (3) e (5), o torque será dado por:

$$
T=\frac{\gamma}{c} G J=\frac{\phi}{L} G J
$$

Duas relações para determinar o torque ao qual o eixo está sendo submetido são possíveis graças às equações anteriores. Sendo que na primeira necessita-se o valor de deformação devido à torção aplicada no eixo e na segunda, faz-se necessário o ângulo de torção. Ambos os métodos chegam ao mesmo resultado.

\section{Métodos de Medição de Torque Diretamente em Eixos Rotativos}

Instrumentos de medição de torque são de grande importância na engenharia, por isso se encontra em universidades e centros de pesquisa vários modelos de ensaios de torção e de medição de torque estático com elevada precisão. Entretanto a medição de torque dinâmico é um desafio, com o constante movimento do eixo rotativo e a necessidade de informações de entrada/saída de dados do sistema no mesmo, agravando a situação no caso da medição em tempo real.

\section{Métodos de Medição por Extensômetros de Resistências}

Os métodos mais utilizados para medição de forças e tensões são os extensômetros de resistência elétrica que apresentam baixo custo, facilidade de instalação e manuseio graças a sua difusão. Durante a medição seu comportamento é razoavelmente linear (BALBINOT; BRUSAMARELLO, 2007).

Aplicando um esforço mecânico em uma direção específica, os extensômetros sofrem uma alteração no valor de sua resistência elétrica, conforme Equação (8):

$$
\frac{\Delta R}{R}=k * \varepsilon
$$

Considerando-se $\varepsilon$ a deformação, $\mathrm{k}$ uma constante de proporcionalidade específica de cada extensômetro que também pode ser chamado de sensibilidade do extensômetro e $\mathrm{R}$ a resistência elétrica. $\mathrm{O}$ extensômetro apresenta uma massa desprezível quando comparado a uma estrutura metálica. Deve ser planejado seu posicionamento, para capturar os dados desejados.

Após o esforço mecânico a deformação da peça em análise e o extensômetro são de mesma grandeza. Conhecendo o novo valor da resistência desse extensômetro, pode-se então definir a deformação da peça. Faz-se necessário fazer compensações devido ao tipo de material em análise, além de correções em 
função das variações de temperatura, pois durante o processo ocorrem variações na temperatura que podem alterar os resultados (DEVITTE, 2013).

A variação de temperatura causa erros nas medições de deformação, não podendo assim obter resultados confiáveis. Uma solução comum é a ligação dos extensômetro em um arranjo denominado ponte de Wheatstone, usando as medições de um modo comparativo, pode-se eliminar os efeitos da variação de temperatura. (BALBINOT; BRUSAMARELLO, 2007).

A ponte de Wheatstone foi proposta inicialmente por Samuel Hunter Christie (1784-1865) em 1833, mas somente em 1858 que Sir Charles Wheatstone (18021875) popularizou seu uso com medições de resistências elétricas com alta resolução (FRADEN, 2004). O arranjo de uma ponte de Wheatstone pode ser observado na Figura 3.

Figura 3 - Ponte de Wheatstone

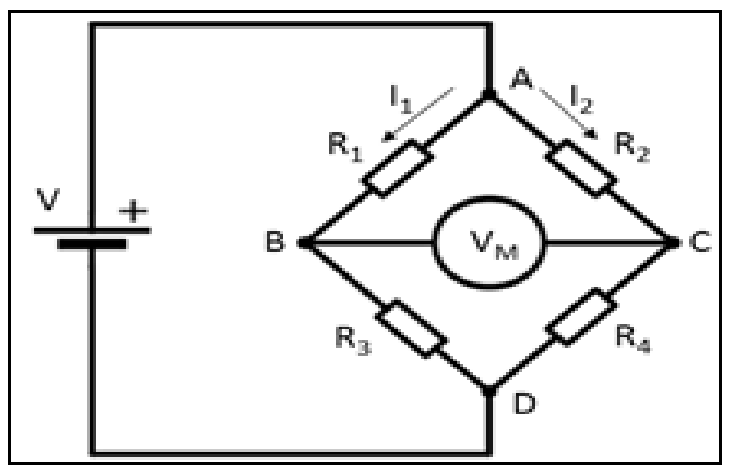

Fonte: Lima, Thiago (2014).

A medição de torque estático realizado em bancadas é relativamente simples, quando comparado a procedimentos semelhantes realizados em um eixo em contínua rotação. Os fios de alimentação se tornam de impossível utilização e novas técnicas entram como possíveis soluções.

\section{Medição de torção via anéis coletores}

O sistema com anéis coletores possui escovas de grafite fixados radialmente ao eixo de rotação. Tais anéis são posicionados de modo a permitir alimentação do circuito (tensão de excitação da ponte), bem como a recepção dos sinais de leitura de tensão elétrica. Embora o sistema de anéis coletores permita a medição da torção nos eixos em rotação, este método apresenta inúmeros inconvenientes. A precisão de medição é reduzida devido ao aumento do ruído causado pelo constante desgaste e aquecimento das escovas de grafite. A grande variedade de junções de materiais e o ruído provocado pelo contato entre anel coleto e escovas, causam alterações nos resultados. O sistema se torna instável quando submetido a vibrações ou alta rotação (BORGES, 2007; CHEONG et al., 1999). A Figura 4 mostra um esboço de como seria. 
Figura 4 - Representação da medição de torção via anéis coletores

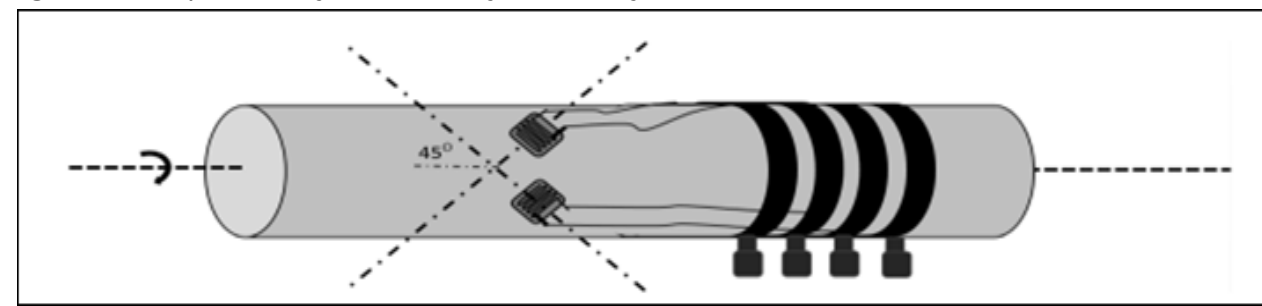

Fonte: Borges, Jacques (2015).

\section{Medição de torção via transdutores circulares}

Uma opção para eliminar o problema de contato deslizante é utilizar transformadores circulares no lugar dos anéis coletores. É muito questionável a relação custo/benefício dos transformadores rotativos. $O$ alinhamento entre as bobinas do transformador pode causar erros, além de ficar susceptível a ruídos, a necessidade de rolamentos e a fragilidade do núcleo dos transformadores limitam a velocidade máxima de rotação do eixo, tornando o sistema mais caro que o convencional com anéis coletores (LIMA FILHO et al., 2011). A Figura 5 ilustra o sistema descrito.

Figura 5 - Representação da medição via transdutores circulares

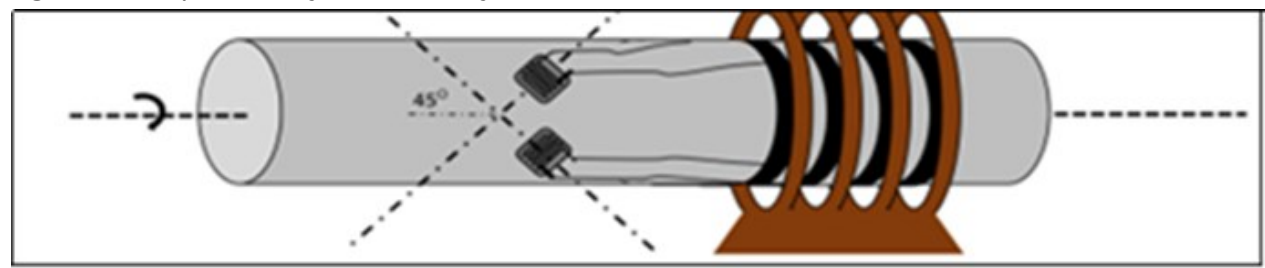

Fonte: Borges, Jacques (2015).

Wassermann et al. (2005) encontraram uma solução para contornar o problema ao utilizar apenas a alimentação do circuito montado sob o eixo, que contava com um sistema de transmissão de dados via infravermelho além dos extensômetros, assim enviando as informações sobre a variação de tensão, descartando a necessidade de transformadores ou anéis de contato deslizante, reduzindo fontes de erro e boa parte do ruído.

\section{Medição de torção via telemetria embarcada}

Bin (2005) também encontrou uma solução, desenvolveu seu trabalho sem transformadores para a alimentação, mas no seu lugar foram introduzidas pequenas baterias no eixo, montado junto com o circuito de medição com extensômetros e o circuito de transmissão de dados. Conseguindo manter uma fonte contínua de tensão, com baixo ruído e poucas oscilações, podendo assim realizar medições com maior precisão. A Figura 6 mostra esse tipo de aplicação. 
Figura 6 - Representação da medição via telemetria embarcada

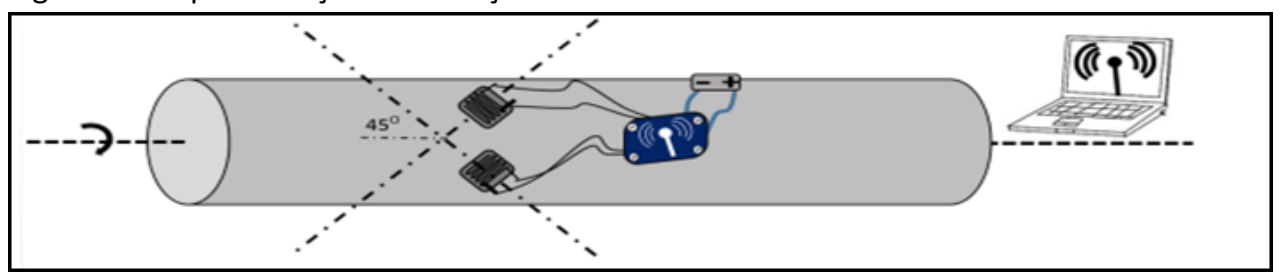

Fonte: Borges, Jacques (2015).

O autor Oliveira (2010) utilizou, além dos extensômetros, um conjunto com um sistema de transmissão a rádio UHF ponto a ponto, com uma faixa de frequência de 902 a $928 \mathrm{MHz}$. Este sistema foi implementado no estudo experimental do torque no laminador de chapas da USIMINAS. Para alimentar este sistema, foi utilizada uma bateria de celular, presa ao eixo em conjunto com o sistema telemétrico. No navio graneleiro Germano Becker, Montfort (2014) também foram utilizados circuitos de telemetria com extensômetros para medir o torque devido ao deslocamento dos propulsores. No mesmo navio Pinheiro (2014) fez um trabalho semelhante, mas seu objetivo foi medição do torque e empuxo dos propulsores do eixo da hélice. Ambos os casos funcionaram com a alimentação dos circuitos de medição, também foi realizada com baterias fixadas no eixo.

Lima Filho et al. (2011) realizaram o trabalho de uma forma semelhante, utilizou extensômetros para medição do torque em unidades de bombeio mecânico, utilizando transmissão de dados via Wi-Fi através de um módulo Xbee, resolvendo o problema de transmissão de dados. Para resolver a questão de alimentação, problema encontrado em todos os outros casos, não foi utilizado bateria para alimentar os circuitos; mas desenvolvido um sistema de auto alimentação, gerando energia com o próprio movimento rotativo do eixo.

\section{Métodos de medição por absorção}

Segundo Brito (1994) os métodos de medição de torque em eixos girantes são recentes, a medição de torque se deu na época da revolução industrial, com a invenção da máquina a vapor.

Segundo Brunetti (2012) na grande maioria das aplicações são utilizados dinamômetros hidráulicos e elétricos, mas o princípio de funcionamento da grande maioria é feito com freios, como o freio de Prony. Os dinamômetros hidráulicos utilizam normalmente o atrito de cisalhamento do fluido contra a carcaça, enquanto os elétricos utilizam a resistência ao movimento de um núcleo dentro do campo eletromagnético para testar a frenagem do motor.

\section{Métodos de medição por sensores piezoelétricos e magnético-elástico}

Os elementos piezoelétricos e os elementos magnético-elásticos são uma solução alternativa à utilização de extensômetros, embora os extensômetros sejam à solução mais utilizada, os piezoelétricos e os magnético-elásticos também podem atuar como transdutores de deformação (BORGES, 2015). 


\section{Métodos de medição por ângulos de torção}

Este princípio não difere muito dos utilizados nos anteriores, será avaliada a deformação causada no eixo devido ao esforço mecânico, sem analisar diretamente o eixo, mas de uma forma que este resultado apareça macroscopicamente. A teoria em que se baseia a medição por torção justifica a possibilidade de obter o valor do torque sobre um eixo a partir da determinação do ângulo decorrente dos esforços de torção (FIGLIOLA; BEASLEY, 2011). Sensores são posicionados em uma distância predeterminada ao longo do eixo. Para obter uma medição mais precisa a faixa usada do eixo para medição deve ser o maior possível, mantendo uma maior distância entre os sensores. Em muitos casos não é possível aumentar essa distância, pois deformações por flexão e efeitos vibracionais não são acentuados em eixos longos e também dificultam a medição. Ângulos menores de 5 graus são vistos como muito pequenos e são muito difíceis de medir, dificultando ainda mais a decisão de distância entre sensores. Representado pela figura abaixo.

Figura 7 - Medição do ângulo de torção via intensidade luminosa

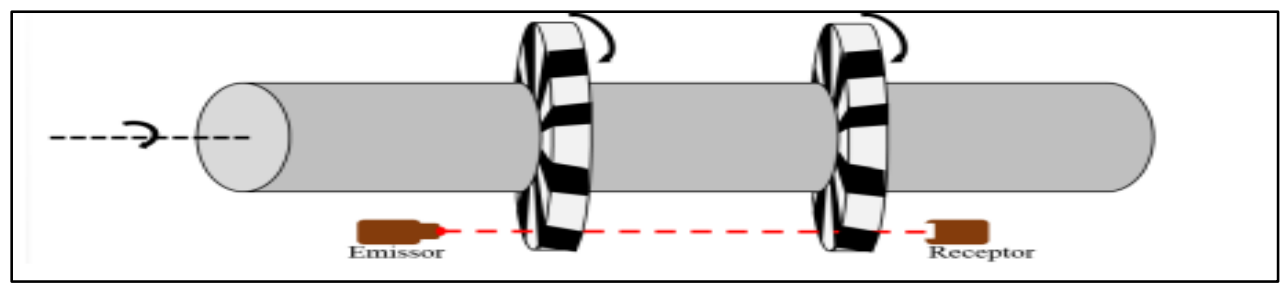

Fonte: Borges, Jacques (2015).

Métodos que utilizam luz em sua medição, denominados ópticos são bastante utilizados pela boa precisão e preços baixos. Os dois métodos ópticos mais importantes são o de medição de intensidade de luz e o de medição de defasagem de luz (NASCIMENTO et al., 2000).

No método de medição de intensidade luminosa, dois discos devem ser posicionados a uma determinada distância, ao longo do eixo. Os discos devem conter partes transparentes ou vazadas, alternando com regiões opacas ou preenchidas, o alinhamento dos discos é imprescindível. Será posicionado em um dos lados, de forma estática, um emissor de luz, enquanto do outro lado, alinhando com o emissor, posiciona-se um receptor de luz, que será capaz de quantificar a intensidade de luz. Durante a rotação sem torque resistivo, não haverá redução da intensidade. Com o aumento do torque, um ângulo de torção será provocado, reduzindo a intensidade de luz captada pelo sensor/receptor. Sendo essa redução proporcional ao torque/ângulo no eixo (BORGES, 2015).

\section{METODOLOGIA DE PROJETO}

Engineering design (projeto de engenharia) é definido como:

O processo da aplicação de diversas técnicas e princípios científicos com o objetivo de definir um dispositivo, um processo ou sistema suficientemente detalhado para permitir sua realização. (Norton, 2010, p.28) 
Sendo este um projeto complexo ou simples, com cálculos ou sem, resolvendo um problema trivial ou de grande relevância. Geralmente os problemas da engenharia exigem uma estruturação do conjunto de problemas, mas na prática quase nunca estes problemas são encontrados de forma estruturada. Na fase de análise, o problema será estruturado nas suas respectivas áreas (mecânica, elétrica ou térmica). Mas, para chegar à etapa de análise o projeto precisa existir, começando na síntese, que é dado como colocar as peças juntas.

Pahl e Beitz (2005) afirmam que o projeto conceitual caracteriza-se como uma etapa de criação onde não se pode levar em consideração apenas ideias fixas, pois a criatividade leva a caminhos inovadores que são passiveis de implementação, ou seja, a liberdade de pensamentos e ideias inovadoras de maneira integradas intensifica o potencial cognitivo e de invenção de uma equipe. Ou seja, nessa etapa do sistema, a criatividade e a inteligência das pessoas envolvidas no projeto estão ligadas diretamente com o resultado do mesmo.

Muitos tipos de "metodologias de um projeto" são pesquisados a fim de solucionar problemas de desestruturação, evitando que a solução apresentada não resolva o que não se propôs, ou não abrangendo o suficiente para resolvê-lo, por isso o problema deve ser bem definido, garantindo que as soluções apresentadas tenham solução direcionada. (NORTON, 2010)

Conforme Pahl e Beitz (2005) a metodologia de projetos de engenharia pode ser dividido em quatro ciclos:

Clarificação das necessidades: definição da tarefa e elaborar as especificações;

Projeto conceitual: identificar os problemas iniciais, pesquisar princípios de solução, combinar e concretizar em variantes de concepção;

Projeto preliminar: desenvolver layouts e formas preliminares, selecionar os melhores layouts, refinar e analisar os critérios técnicos e econômicos;

Projeto detalhado: Verificar todos os documentos e finalizar os detalhes de documentos de produção.

As etapas desse projeto, vistas no próximo quadro, não podem ser utilizadas de forma linear, mas sim de forma iterativa, ou seja, em alguns momentos é necessário voltar para a primeira etapa ou repetir etapas anteriores. (NORTON, 2010)

Segundo Norton (2010) esta fase do projeto é baseada na criatividade, por isso muito gratificante, mas também a mais difícil. Diz também que muitos estudos e pesquisas sobre a criatividade são feitas, mas não existem fortes evidências sobre elas, mas acredita que muito da criatividade é perdida com o tempo, tendo seu pico na infância. Porém acredita que a capacidade criativa pode ser aumentada com algumas técnicas e da alguns exemplos. Para ele o processo de idealização e invenção pode ser subdividido em quatro passos, estes passos estão descritos no Quadro 1. 
Quadro 1 - Subdivisões de idealização

\begin{tabular}{|c|c|}
\hline № & Subdivisão \\
\hline $5 a$ & Geração de ideias. \\
\hline $5 b$ & Frustração \\
\hline $5 c$ & Incubação. \\
\hline $5 d$ & Eureca! \\
\hline
\end{tabular}

Fonte: Norton (2010).

Considerado pelo autor supracitado o mais difícil desses passos, a geração da ideia, se mostra um desafio mesmo para os mais criativos, quando postos a trabalhar sobre pressão. Recomenda deixar de lado o julgamento, ou seja, não usar seu lado crítico, com a intenção de criar uma gama de ideias por mais absurdas que algumas pareçam, podem abrir portas para pensar em algo funcional mais tarde.

Nem sempre se pode contar com um grupo de pesquisa então quando o projetista está sozinho, surge à necessidade de outras técnicas. O autor sugere analogias, inversões e sinônimos. Analogias são usadas para fugir do ponto de vista inicial, convertendo um sistema mecânico em um sistema elétrico, ou fluido. A inversão, como diz o autor, vira do avesso o projeto, o que é movido, agora faz o movimento e vice-versa. Para usar os sinônimos, um ponto enunciado do problema deve ser definido, então substituindo o verbo de ação, por todos os sinônimos encontrados, ou de função parecida, novas ideias podem surgir. (NORTON, 2010)

De Acordo com Norton (2010) independente das técnicas utilizadas, em algum momento as ideias vão esgotar, iniciando então a etapa de frustração, onde se mais tempo for dedicado a encontrar a solução, só vai gerar mais frustração, o autor recomenda abandonar o problema e fazer algo diferente, passando para o passo de incubação, deixando o subconsciente cuidar do assunto e achar a melhor solução. Em algum momento surgirá uma ideia obvia e correta à primeira vista, etapa chamada de "Eureca!" pelo autor, esta ideia deve passar para próxima etapa, a análise, se encontrar falhas nessa solução, o projeto deve ser interrompido e a idealização deve ser realizada novamente, até encontrar a solução.

Esta etapa retrata o surgimento do problema, é o pontapé inicial do projeto, normalmente essa ideia vem de terceiros, mas algumas vezes por análise própria apresenta-se a necessidade de um melhoramento, aquele sentimento de "Posso melhorar isso.". Em relação à etapa inicial, Norton, (2010) afirma:

Esse primeiro passo em geral é dado quando alguém, como um chefe ou cliente, pede-lhe "Nós precisamos de...". Essa frase normalmente será breve e sem muitos detalhes. Ela estará longe de lhe fornecer um problema estruturado. Pode-se, Por exemplo, ouvir "Precisamos de um cortador de grama melhor". (Norton, 2010, p.28)

Durante esta fase de pesquisa, dados sobre física, química ou outros aspectos devem ser levantados, mas é importante saber se existe solução para o problema, ou algum problema parecido. No caso de encontrar uma solução pronta no mercado, o autor sugere compra-lo, pois será mais econômico que projetar e construir um novo. Mas, o mais provável é que a solução não seja encontrada 
terceirizada e projetar o novo seja a única saída, mesmo assim, o estudo de produtos e tecnologias semelhantes é fortemente recomendado. (NORTON, 2010)

Ainda de acordo com o autor supracitado, patentes e publicações técnicas são ótimas fontes de informação e ambas estão disponíveis na Internet. Conforme descrito por Norton, (2010, p.29) "A Internet torna fácil encontrar documentos sobre o item comprado como engrenagens, rolamentos e motores para seu projeto de máquina. Além disso, muitas informações sobre o projeto de máquinas estão disponíveis na Internet".

Para Pahl et al. (2005), para analisar o problema de um novo produto é importante realizar levantamentos de dados através de uma lista de requisitos onde constem os dados que atendam aos requisitos básicos de funcionamento do equipamento, tornando viável o produto final, estes dados vão auxiliar o projetista e garantirão que todas as necessidades do cliente sejam compridas, portanto, é recomendado que se construísse tal lista conforme a Figura 8, onde na coluna de característica principal apresenta-se o grupo de parâmetros a analisar e a sua direita encontram-se os respectivos dados do segmento, ainda explica a possiblidade de acoplar uma coluna com a real necessidade do parâmetro, em desejo ou exigência.

Figura 8 - Linha mestre de requisitos

\begin{tabular}{|c|c|}
\hline $\begin{array}{l}\text { Característica } \\
\text { principal }\end{array}$ & Exemplos \\
\hline Geometria & $\begin{array}{l}\text { Tamanho, altura, largura, comprimento, diâmetro, demanda de espaço, quantidade, disposição, conexão, supres } \\
\text { são e ampliação }\end{array}$ \\
\hline Cinemática & Tipo de movimento, direção do movimento, velocidade, aceleração \\
\hline Forças & $\begin{array}{l}\text { Magnitude da força, direçăo da força, frequêência da força, peso, carregamento, deformação, rigidez, propriedades } \\
\text { elásticas, estabilidade, ressonância }\end{array}$ \\
\hline Energia & $\begin{array}{l}\text { Potência, eficiência, perdas por atrito, ventilação, variáveis de estado, como pressão, temperatura, humidade, } \\
\text { aquecimento, resfriamento, energia de abastecimento, armazenamento, capacidade, conversão de energia }\end{array}$ \\
\hline Matéria & $\begin{array}{l}\text { Propriedades fisicas e quimicas do produto de entrada e saida, material auxiliar, substâncias prescritas (lei de } \\
\text { alimentos e semelhantes), fluxo de material e transporte }\end{array}$ \\
\hline Sinal & Sinais de entrada e saída, tipo de mostrador, aparelhos para produção e monitoramento, forma do sinal \\
\hline Segurança & $\begin{array}{l}\text { Principios de segurança diretos, sistemas protetores, segurança industrial, segurança no trabalho, segurança } \\
\text { ambiental }\end{array}$ \\
\hline Ergonomia & Relação homem-máquina: operação, tipos de operação, disposição clara, iluminação, desenho \\
\hline Produção & $\begin{array}{l}\text { Limitações do local da produção, máxima medida fabricável, processo produtivo preferido, meios de produção, } \\
\text { qualidade possivel e tolerâncias }\end{array}$ \\
\hline Controle de qualidade & Possibilidades de teste e medição, prescrições especiais (TÜV, ASME, DIN, ISO, especificações AD) \\
\hline Montagem & $\begin{array}{l}\text { Prescriçōes especiais de montagem, montagem, embutimento, montagem do canteiro de obras, bases de } \\
\text { equipamentos }\end{array}$ \\
\hline Transporte & $\begin{array}{l}\text { Limitações através de guinchos, bitola ferroviária, vias de transporte por tamanho e peso, tipo e restrições do } \\
\text { transporte }\end{array}$ \\
\hline Operação & Baixo ruído, taxa de desgaste, aplicação e domínio de utilização, condições de uso (atmosfera sulfurosa, trópicos) \\
\hline Manutençăo & Livre de revisão ou número e intervalo de tempo entre revisões, inspeção, troca, conserto, pintura, lavagem \\
\hline Reciclagem & Reaproveitamento, reprocessamento, disposiçăo final, armazenamento \\
\hline Custos & Máximos custos de fabricação, custo de ferramentas, investimento, amortização \\
\hline Prazo & Fim do desenvolvimento, plano em rede para etapas intermediárias, prazo de entrega \\
\hline
\end{tabular}

Fonte: PAHL et al. (2005, p.120).

Para a definição do objetivo segundo Norton (2010) define que os mesmos precisam de 3 características importantes: Ele deve ser conciso, abrangente e não possuir elementos que preveem a solução.

Conforme Pahl et al. (2005), para auxiliar a criação da linha mestre é importante conhecer a função do produto em desenvolvimento, deste modo, é sugerido criar um diagrama conhecido como função global, Figura 9, onde os requisitos e funções de um equipamento, conjunto ou subconjunto são 
representados com a inter-relação objetivada entre a entrada e a saída de um sistema tendo a função principal como a global e as demais que possibilitam a existência da global exibidas em subconjuntos.

Figura 9 - Função global

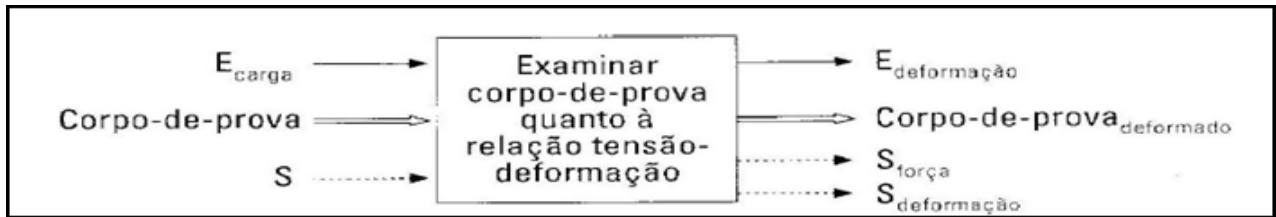

Fonte: PAHL et al. (2005, p.120).

Em muitos casos, como na Figura 9, é possível realizar a abertura da função global em um novo leque de funções, de tal modo, que se torne mais visível e explicativo os procedimentos necessários ao funcionamento do produto, portanto na Figura 10, a máquina realizou uma série de funções e têm-se os passos para chegar aos resultados de deformação do corpo de prova, para isto foi necessário inserir o corpo de prova no sistema, e este será carregado e deformado, para isto é necessário à entrada de energia (E carregamento) que ao entra um sinal de comando ( $S$ deformação) realizara a transformação da energia em força de deslocamento, assim cumprirá a função global de deformar o corpo de prova e realizar a medição da tensão necessária sendo assim o resultado será um sinal de saída ( $\mathrm{S}$ força) com os dados necessários para uma máquina de ensaio. É valido ressaltar que esta linha logica facilita no desenvolvimento do produto e deve ser adaptada para cada caso em estudo.

Figura 10 - Sub função (função principal) de uma máquina de ensaio

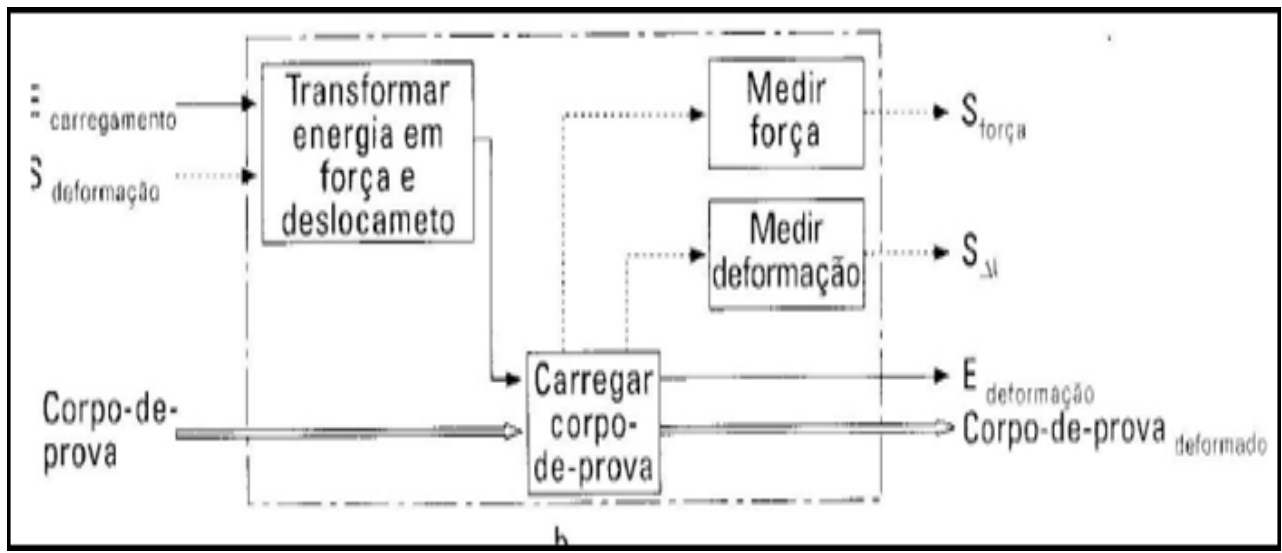

Fonte: Pahl et al. (2005, p.120).

Segundo Pahl et al. (2005) é importante encontrar possíveis soluções para cada etapa, é sugerido à criação de uma tabela, Figura 11, onde estejam contidas na coluna as sub funções apresentando o problema e na referida linha estão soluções de funcionalidade possíveis, apresentando de forma resumida as ideias existentes ou que serão criadas para a realização de tal tarefa, nesta fase é importante organizar a coluna de forma que atenda a ordem funcional do produto final, facilitando a ligação de cada sub função. 
Figura 11 - Estrutura funcionalidade

\begin{tabular}{|c|c|c|c|c|c|}
\hline $\begin{array}{l}\text { Solução } \\
\text { Subfunção }\end{array}$ & 1 & 2 & 3 & 4 & 5 \\
\hline $\begin{array}{l}\text { A } \\
\text { Gerar } \\
\text { movimento } \\
\text { de rolamento e } \\
\text { deslizamento }\end{array}$ & Manivela & $\begin{array}{l}\text { Mecanismo } \\
a^{\text {senoidal }}\end{array}$ & manivela-balancim & $=\sum_{\text {Chapa inclinada }}$ & 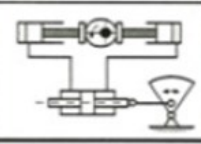 \\
\hline $\begin{array}{l}\text { B } \\
\text { Gerar força } \\
\text { normal }\end{array}$ & & & $\begin{array}{l}\text { Principio Sirex } \\
\text { Patim giratório }\end{array}$ & & $\begin{array}{l}\text { Circuito hidráulico } \\
\text { do pulso }\end{array}$ \\
\hline $\begin{array}{l}\text { C } \\
\text { Aplicar força } \\
\text { normal }\end{array}$ & Guia plana & $\frac{x}{\text { Capsulas esfericas }}$ & Corroia el Isstica & & \\
\hline $\begin{array}{l}\text { D } \\
\text { Medir força } \\
\text { normal }\end{array}$ & $\underbrace{\text { Extensômetro na }}_{\text {trajetória da força }}$ & 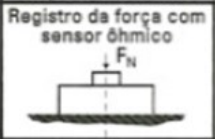 & 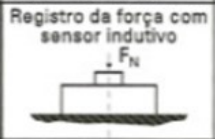 & 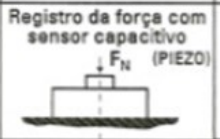 & \\
\hline $\begin{array}{l}\mathrm{E} \\
\text { Medir o atrito }\end{array}$ & 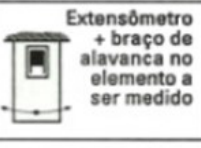 & 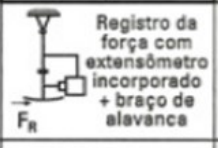 & ₹ $\begin{array}{c}\text { Registro da } \\
\text { força por } \\
\text { meio de } \\
\text { armadura } \\
\text { trannsversal } \\
\text { induzida }\end{array}$ & Extensometro direto & $\begin{array}{l}\text { Corpo-de-prova } \\
\text { Sensor de torque } \\
\text { (extensometro/Plezo) }\end{array}$ \\
\hline $\begin{array}{l}\text { F } \\
\text { Medir } \\
\text { temperatura }\end{array}$ & $\begin{array}{l}\text { Condutor resistivo } \\
\text { (0t } 100 \text { etc.) }\end{array}$ & Resistência NTC & Resistência PTC & Elemento térmico & \\
\hline
\end{tabular}

Fonte: PAHL et al. (2005, p.124).

A combinação de soluções globais é apresentada de forma sistemática na Figura 12.

Figura 12 - Combinações sistemáticas globais

\begin{tabular}{|c|c|c|c|c|c|c|c|}
\hline Funç8 & Soluçס̄es & 1 & 2 & $\cdots$ & j & $\ldots$ & $\mathrm{m}$ \\
\hline \begin{tabular}{|l|}
1 \\
\end{tabular} & \begin{tabular}{|l|}
$F_{1}$ \\
\end{tabular} & $\mathrm{E}_{11} \mathrm{O}$ & $\mathrm{E}_{12}$ & & $E_{11}$ & & $E_{1 m}$ \\
\hline 2 & $F_{2}$ & $E_{21} \frac{a}{\alpha}$ & $E_{22}$ & & $E_{21}$ & & $E_{2 m}$ \\
\hline : & & $\vdots$ & : & $\gamma$ & $\vdots$ & & $\vdots$ \\
\hline j & $F_{i}$ & $E_{i 1}$ & $\mathrm{E}_{12}{ }^{3}$ & & $E_{i j}$ & & $E_{i m}$ \\
\hline$\vdots$ & & $\vdots: 0$ & $\vdots$ & & "S & & $\vdots$ \\
\hline $\mathrm{n}$ & $F_{n}$ & $E_{n 1}^{\dagger}$ & $E_{n 2}{ }^{n-}$ & & $E_{n j}$ & & $E_{n m}$ \\
\hline
\end{tabular}

Fonte: Pahl et al. (2005, p.174).

Com os dados já contidos na estrutura de funcionalidade o próximo passo, segundo Pahl et al. (2005), é criar linhas que liguem as subjunções que cumpram a função global e sejam compatíveis com a combinação criada.

Ainda Pahl et al. (2005), afirma que a diferença entre as combinações deve ser quantificada, sendo criada uma distribuição que defina valores para avaliar os critérios exigidos sobre o produto, desde o modelamento até a fabricação. Por exemplo, essa avaliação geralmente envolve a atribuição de valores técnicos, ecológicos, econômicos e de segurança.

Uma forma de classificar cada fator é seguir a lista de escala de valores, Figura 13, que correlaciona analiticamente à viabilidade de tal parâmetro, partindo de insatisfatório recebendo zero ponto e chegando ao ideal com dez pontos. 
Figura 13 - Escala de Valores

\begin{tabular}{|c|c|c|c|c|}
\hline \multicolumn{5}{|c|}{ ESCALA DE VALORES } \\
\hline$P t$ & $\begin{array}{l}\text { Análise de valor útil } \\
\text { Significado }\end{array}$ & $P t$ & $\begin{array}{l}\text { Diretriz VDI } 2225 \\
\text { Significado }\end{array}$ & \\
\hline 0 & $\begin{array}{l}\text { Soluçāo absolutamente } \\
\text { não utilizável }\end{array}$ & \multirow[t]{2}{*}{0} & \multirow[t]{2}{*}{ insatisfatória } & \\
\hline 1 & Solução muito deficiente & & & \\
\hline 2 & Solução fraca & \multirow[t]{2}{*}{1} & \multirow{2}{*}{\multicolumn{2}{|c|}{$\begin{array}{l}\text { solução ainda } \\
\text { sustentável }\end{array}$}} \\
\hline 3 & Solução sustentável & & & \\
\hline 4 & Solução suficiente & \multirow{2}{*}{2} & \multirow{2}{*}{ suficiente } & \\
\hline 5 & Solução satisfatória & & & \\
\hline 6 & $\begin{array}{l}\text { Solução boa com } \\
\text { poucas falhas }\end{array}$ & \multirow[t]{2}{*}{3} & \multirow[t]{2}{*}{ boa } & \\
\hline 7 & Solução boa & & & \\
\hline 8 & Solução muito boa & \multirow{3}{*}{4} & \multirow{3}{*}{\multicolumn{2}{|c|}{ muito boa (ideal) }} \\
\hline 9 & $\begin{array}{l}\text { Solução excedendo os } \\
\text { requisitos }\end{array}$ & & & \\
\hline 10 & Solução ideal & & & \\
\hline
\end{tabular}

Fonte: Phal et al. (2005, p.80).

Visualiza-se um exemplo prático na Figura 14.

Figura 14 - Lista de avalição

\begin{tabular}{|c|c|c|c|c|c|c|c|c|c|c|}
\hline \multirow{2}{*}{\multicolumn{2}{|c|}{$\begin{array}{c}\text { Critérios de } \\
\text { avaliaçẫo }\end{array}$}} & \multirow[b]{3}{*}{ Fator } & \multicolumn{2}{|l|}{ Parâmetros } & \multicolumn{3}{|c|}{ Variante $V_{1}(p . e x . M)$} & \multicolumn{3}{|c|}{ Variante $V_{2}\left(p . e x, M_{1}\right)$} \\
\hline & & & & & carac- & valor & valor & carac- & valor & valor \\
\hline Ne. & & & & Unidade & $\theta_{1}$ & $w_{1}$ & $w_{g_{11}}$ & $\theta_{2}$ & $w_{2}$ & $w g_{2}$ \\
\hline 1 & $\begin{array}{l}\text { baixo consumo de } \\
\text { combustivel }\end{array}$ & 0,3 & $\begin{array}{l}\text { consumo de } \\
\text { combustivel }\end{array}$ & $9 / \mathrm{kWh}$ & 240 & 8 & 2,4 & 300 & 5 & 1,5 \\
\hline 2 & construçăo leve & 0,15 & potência especifica & $\mathrm{kg} / \mathrm{kW}$ & 1,7 & 9 & 1,35 & 2,7 & 4 & 0,6 \\
\hline 3 & fácil fabricaçã̃o & 0,1 & $\begin{array}{l}\text { simplicidade das } \\
\text { peças fundidas }\end{array}$ & - & $\begin{array}{l}\text { compli- } \\
\text { cado }\end{array}$ & 2 & 0,2 & médio & 5 & 0,5 \\
\hline 4 & $\begin{array}{l}\text { elevado tempo } \\
\text { de vida }\end{array}$ & 0,2 & $\begin{array}{l}\text { tempo de } \\
\text { vida }\end{array}$ & $\begin{array}{l}\text { quilome- } \\
\text { tragen }\end{array}$ & 80.000 & 4 & 0,8 & 150.000 & 7 & 1,4 \\
\hline 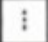 & $\vdots$ & $\vdots$ & $\vdots$ & $\vdots$ & $\vdots$ & $\vdots$ & $i$ & $\vdots$ & $\vdots$ & $\vdots$ \\
\hline$i$ & & 9 & & & $\theta_{11}$ & $w_{11}$ & $w g_{1}$ & $\theta_{2}$ & $w_{2}$ & $\mathrm{wg}_{2}$ \\
\hline$\vdots$ & $\vdots$ & $i$ & $\vdots$ & $\vdots$ & $\vdots$ & $\vdots$ & 1 & $\vdots$ & $\vdots$ & $\vdots$ \\
\hline$n$ & & $g_{n}$ & & & $e_{n 1}$ & $w_{n t}$ & $w_{n+1}$ & $e_{n 2}$ & $w_{n 2}$ & $w_{12}$ \\
\hline & & $\sum_{i=1}^{n} g=1$ & & & & $\begin{array}{l}G W_{1} \\
W_{1}\end{array}$ & $\begin{array}{l}\text { GWg } \\
W g_{1}\end{array}$ & & $\begin{array}{l}G W_{2} \\
W_{2}\end{array}$ & $\begin{array}{l}G w_{h} \\
W_{g h}\end{array}$ \\
\hline
\end{tabular}

Fonte: Phal et al. (2005, p.81).

Ainda segundo Pahl et al. (2005), para realizar atribuição de pontos é preciso montar um esquema que será preenchido conforme a escala de valores, baseado nos conhecimentos do projetista a respeito do produto, do local de fabricação e da capacidade de mão de obra. 


\section{METODOLOGIA}

O método de abordagem é dividido em dois itens muito distintos: qualitativos e quantitativos. O método utilizado neste trabalho é a pesquisa quantitativa que segundo Polit et al. (2004) tem como base o pensamento positivista lógico.

Enfatiza a lógica e as características mensuráveis da experiência humana. Esta modalidade prioriza a objetividade na coleta e na análise dos dados além de usar procedimentos estruturados e instrumentos formais para a coleta dos dados.

Em síntese de acordo com Fonseca (2002) a pesquisa quantitativa recorre à linguagem matemática para definir as causas de um fenômeno.

De acordo com Gil (2007) com base nos objetivos, podem-se classificar as pesquisas em três grupos:

a) Pesquisa exploratória;

b) Pesquisa explicativa;

c) Pesquisa descritiva.

O tipo de pesquisa utilizado no trabalho é a explicativa, visto que segundo Gil (2007) este tipo de pesquisa visa identificar os fatores que determinam ou contribuem para a ocorrência dos fenômenos. Pesquisas explicativas podem ser classificadas como experimentais.

Partindo para a metodologia de procedimentos, podem-se citar vários tipos de pesquisas:

a) Pesquisa experimental;

b) Pesquisa bibliográfica;

c) Pesquisa documental;

d) Pesquisa de campo;

e) Pesquisa de levantamento;

f) Estudo de caso;

g) Pesquisa participante;

h) Pesquisa ação.

Este projeto tem caráter experimental, pois de acordo com Gil (2007) a pesquisa experimental baseia-se em determinar um objeto de estudo, selecionar as variáveis que são capazes de influenciá-lo, definir as formas de controle e de observação dos efeitos que a variável produz no objeto.

O projeto do dinamômetro foi desenvolvido para medir o torque no processo de furação. Este equipamento foi desenvolvido para ser adaptado no centro de usinagem Romi Polaris V400.

$\mathrm{Na}$ primeira etapa do projeto foram analisadas as soluções existentes no mercado e então aplicado a técnica de projeto conceitual, onde foi obtido o esboço da concepção do projeto.

Foi aplicada a técnica do brainstorming, indicada por Norton, após utiliza-se a metodologia de Pahl e Beitz. Finalizou-se o projeto conceitual, gerou-se a ideia de projeto definitivo, detalharam-se os desenhos com dimensões e tolerâncias de 
fabricação. Na etapa final, construiu-se o protótipo do equipamento e posteriormente deverá ser realizado testes de funcionamento.

\section{CENTRO DE USINAGEM}

A máquina a ser implementada com o dinamômetro, será um centro de usinagem vertical Romi Polaris V400, tendo este um curso de trabalho de $700 \times 420 \times 600$, com uma dimensão de mesa de 400×900 e altura máxima de trabalho de 350 milímetros.

A ferramenta de trabalho pode atingir a rotação máxima de 6 mil rotações por minuto. Conforme Figura 15.

Figura 15 - Produtos do mercado

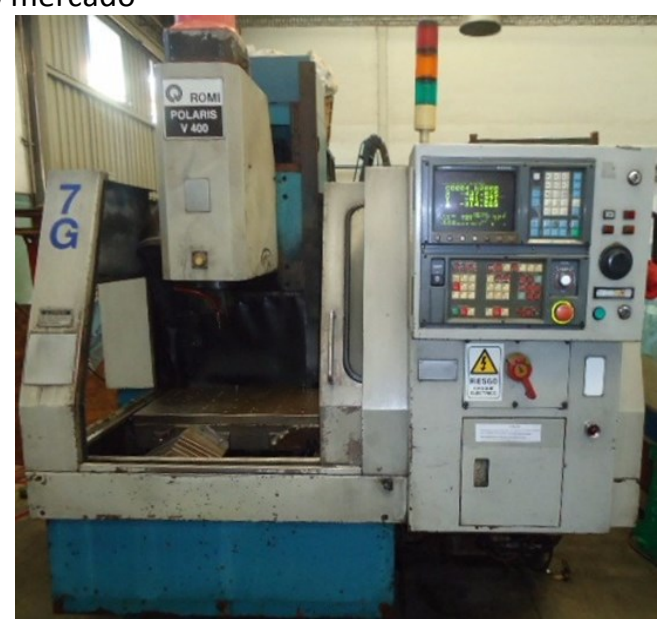

Fonte: Ebay (2016).

\section{DESENVOLVIMENTO}

Neste capítulo as etapas de desenvolvimento do projeto serão demonstradas e explicadas. A primeira etapa sugerida anteriormente foi estudo sobre os produtos existentes no mercado, conforme Figura 16.

Figura 16 - Produtos do mercado

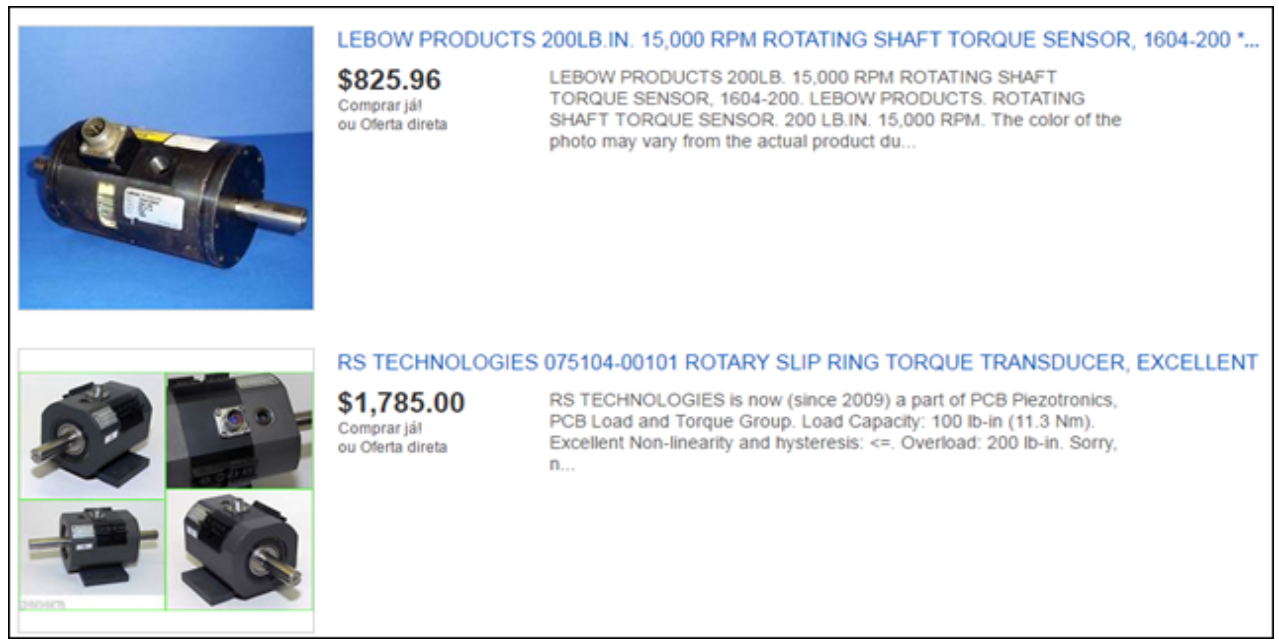

Fonte: Ebay (2016). 
Dentre os produtos mostrados na Figura 15, o primeiro não atende os requisitos básicos, pois não tem saída de movimento. A maioria dos produtos encontrados no mercado não atendem requisitos para o funcionamento do mesmo.

Poucos encontrados como o segundo item da lista, atendem as características básicas, mas possuem outros problemas, como tamanho e peso, o maior problema acaba sendo os preços, custando entre 2 a 6 mil reais. 0 preço do produto da imagem em reais esta aproximadamente $\mathrm{R} \$ 6.227,00$.

Para aprimorar o modelo é necessário partir da metodologia estudada de Pahl e Beitz onde o primeiro passo no desenvolvimento conceitual é a criação da linha mestre de requisitos, Quadro 2, onde constarão dados sobre o futuro do modelo desejado.

Quadro 2 - Parâmetros mestres para o produto

\begin{tabular}{|c|c|c|c|}
\hline $\begin{array}{c}\text { Característica } \\
\text { Principal }\end{array}$ & $\begin{array}{c}\text { Características } \\
\text { Principal }\end{array}$ & $\begin{array}{l}\text { Desejada/ } \\
\text { Exigida }\end{array}$ & Requisito \\
\hline \multirow{3}{*}{ Geometria } & Altura & $\mathrm{E}$ & Máximo 200 mm \\
\hline & Diâmetro (carcaça) & $\mathrm{E}$ & Máximo 200 mm \\
\hline & Diâmetro (eixo) & $\mathrm{D}$ & $15 \mathrm{~mm}$ \\
\hline Forças & Torque máximo & $\mathrm{D}$ & 10 N.m \\
\hline \multirow{5}{*}{ Material } & Eixo & $\mathrm{D}$ & Material disponível \\
\hline & Carcaça & D & Material disponível \\
\hline & Mola & $\mathrm{D}$ & Aço Mola \\
\hline & Guia deslizante & D & Nylon \\
\hline & Outros componentes & $\mathrm{D}$ & Aço 1020 ou terceirizado \\
\hline Sinal & Leitor de posição & $\mathrm{D}$ & Óptico \\
\hline \multirow{3}{*}{ Produção } & Usinagem & $\mathrm{D}$ & Eixo, Carcaça \\
\hline & Montagem & $\mathrm{E}$ & Manual \\
\hline & Manutenção & $\mathrm{E}$ & Manual \\
\hline
\end{tabular}

Fonte: $\mathrm{O}$ autor (2016).

Prosseguindo com o desenvolvimento conceitual, é preciso elaborar a função global do conjunto. Na figura 17 é possível observar que o objetivo principal é medir o torque necessário em processo de furação. Tendo como entrada, uma carga de torque (E) que é fornecida pela rotação da furadeira ou centro de usinagem, este atua sobre a ferramenta protótipo, que resiste ao esforço sofrendo uma deformação elástica (E e S deformação).

Figura 17 - Função Global

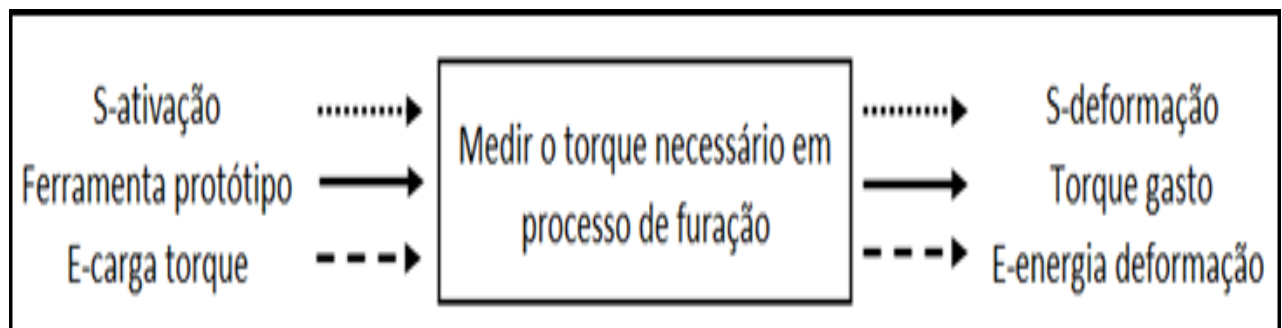

Fonte: O autor (2016). 
Para melhor compreensão do sistema e melhor planejamento, uma nova sistematização de função global deve ser feita, mas com sub funções, possibilitando visualizar o procedimento detalhado para assim ver o que a função global necessita para ser atendida, como pode ser visto na Figura 18.

Figura 18 - Função global e suas subfunções

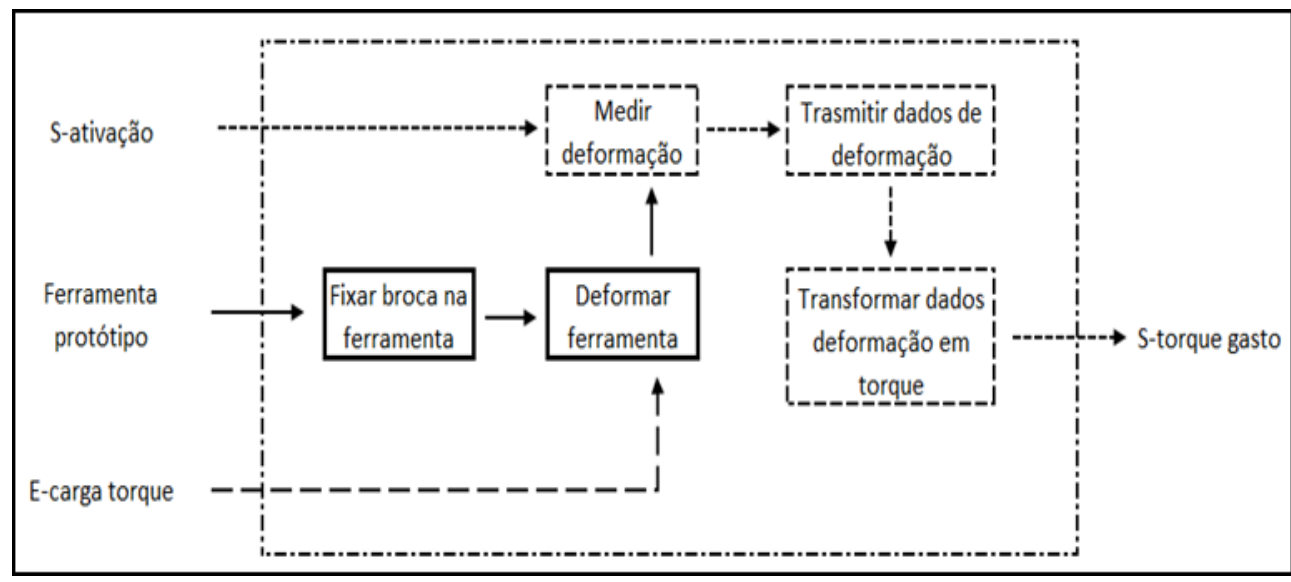

Fonte: O autor (2016).

O eixo árvore do centro de usinagem vertical será o responsável por transmitir força ao sistema em forma de carga de torque $(E)$, quando o processo de furação for efetuado, a resistência do material produzirá uma deformação na ferramenta protótipo, esta deformação será medida e os dados serão transmitidos para um equipamento externo que os transformará em parâmetros de torque, cumprindo a função global.

O próximo passo segundo Pahl e Beitz é construir uma estrutura de funcionalidade, Quadro 3, onde cada sub função apresenta as soluções disponíveis, baseando-se principalmente na viabilidade construtiva.

Quadro 3 - Estrutura de funcionalidade

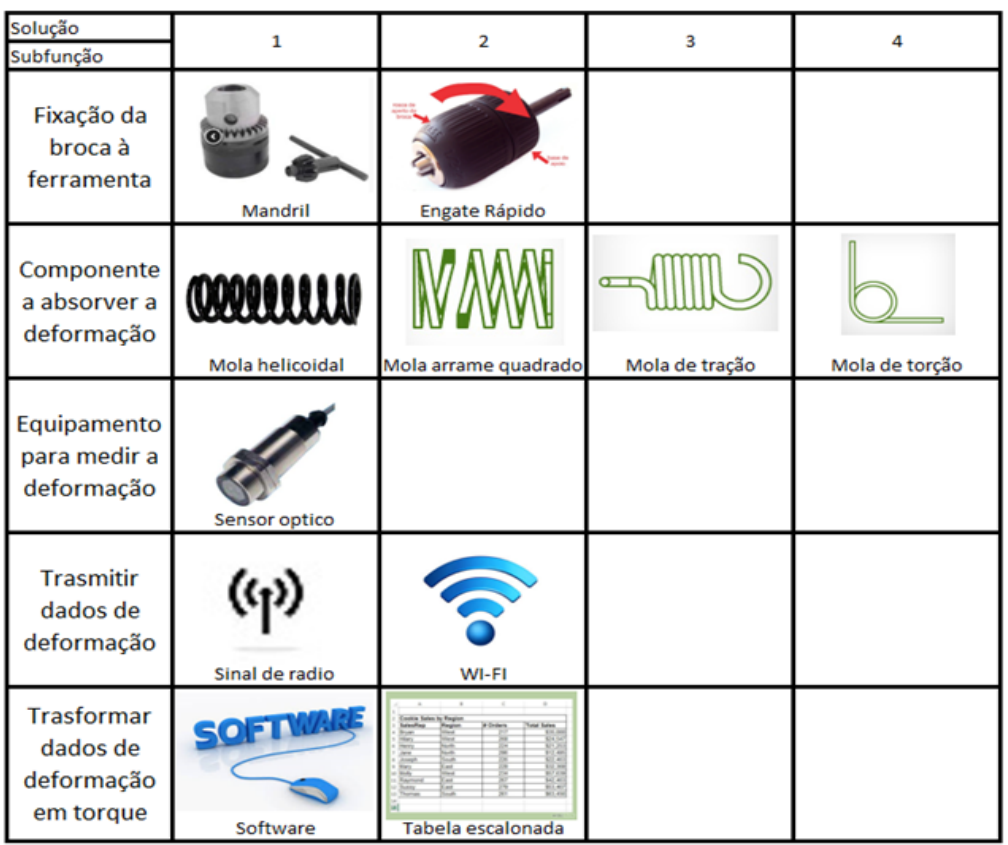

Fonte: O autor (2016). 
Com as devidas soluções encontradas é importante avaliar cada solução e sua capacidade de realizar a função desejada.

O Quadro 4 apresenta pesos e notas para cada sub função e a solução possível, este modelo é adaptado da metodologia de Pahl e Beitz.

Quadro 4 - Avaliação de funcionalidade

\begin{tabular}{|c|c|c|c|c|c|}
\hline \multicolumn{6}{|c|}{ AVALIAÇÃO DE FUNCIONALIDADE } \\
\hline \begin{tabular}{|l} 
Solução \\
subfunção \\
\end{tabular} & 1 & 2 & 3 & 4 & PARAMETROS AVALIATIVOS \\
\hline \multirow{6}{*}{$\begin{array}{c}\text { FIXAÇÃO DA } \\
\text { BROCA }\end{array}$} & 3 & 3 & & \multicolumn{2}{|r|}{ Custo } \\
\hline & 2 & 3 & & & Capacidade Mecânica \\
\hline & 3 & 4 & & & \multirow{2}{*}{\begin{tabular}{|l} 
Facilidade em acoplar ao projeto \\
Velocidade de utilização
\end{tabular}} \\
\hline & 2 & 4 & & & \\
\hline & 4 & 4 & & & Disponibilidade de mercado \\
\hline & 14 & 18 & & & TOTAL \\
\hline \multirow{6}{*}{$\begin{array}{l}\text { COMPONENTES } \\
\text { A ABSORVER A } \\
\text { DEFORMÇÃO }\end{array}$} & 4 & 2 & 4 & 4 & Custo \\
\hline & 2 & 4 & 3 & 2 & Capacidade Mecanica \\
\hline & 3 & 4 & 1 & 0 & Facilidade em acoplar ao projeto \\
\hline & 4 & 4 & 3 & 2 & Facilidade de manutenção \\
\hline & 4 & 2 & 4 & 2 & Disponibilidade de mercado \\
\hline & 17 & 16 & 15 & 10 & \begin{tabular}{|c|} 
TOTAL \\
\end{tabular} \\
\hline \multirow{5}{*}{$\begin{array}{l}\text { TRAMISOR DE } \\
\text { DADOS }\end{array}$} & 3 & 2 & & \multicolumn{2}{|r|}{ Custo } \\
\hline & 4 & 3 & & & \multirow{2}{*}{\begin{tabular}{|l} 
Facilidade em acoplar ao projeto \\
Velocidade de utilização
\end{tabular}} \\
\hline & 4 & 4 & & & \\
\hline & 4 & 3 & & & Disponibilidade de mercado \\
\hline & 15 & 12 & & & \begin{tabular}{|c|} 
TOTAL \\
\end{tabular} \\
\hline \multirow{6}{*}{$\begin{array}{l}\text { TRASFORMAR } \\
\text { DADOS EM } \\
\text { TORQUE }\end{array}$} & 3 & 3 & & & \multirow{2}{*}{\begin{tabular}{|l} 
Custo \\
Facilidade de utilização
\end{tabular}} \\
\hline & 4 & 2 & & & \\
\hline & 3 & 3 & & & \begin{tabular}{|l|} 
Facilidade de utilização \\
Facilidade em acoplar ao projeto \\
\end{tabular} \\
\hline & 4 & 2 & & & Velocidade de utilização \\
\hline & 3 & 4 & & & Facilidade de criação \\
\hline & 17 & 14 & & & \begin{tabular}{|r} 
TOTAL \\
\end{tabular} \\
\hline \multirow{4}{*}{ LEGENDA } & 0 & INSATI & RIO & & \multirow{4}{*}{$\begin{array}{c}\text { *OBS:A solução com } \\
\text { maior nota final é a } \\
\text { melhor opção para cada } \\
\text { sub função. }\end{array}$} \\
\hline & 1 & SOLUÇ & NDA & ITÁVEL & \\
\hline & $\frac{2}{3}$ & \begin{tabular}{|l|} 
SUFICI \\
BOA
\end{tabular} & & & \\
\hline & 4 & MUITO & IDEA & & \\
\hline
\end{tabular}

Fonte: $\mathrm{O}$ autor (2016).

Para fixação da broca, o engate rápido teve maior nota em "capacidade mecânica" devido ao fato de ter menor problema de desgaste em seu mecanismo de fixação, além disso, recebeu maior nota pela praticidade de não precisar chave para fixar a ferramenta, ganhando ponto em "facilidade de acoplar ao projeto". Por sua rapidez de fixação e troca de ferramenta teve melhor pontuação de "velocidade de utilização", sendo a escolhida por seus vários pontos positivos.

Durante a escolha da mola quase todas as opções tinham pontos positivos, entretanto os pontos determinantes foram o "custo" e a "disponibilidade no mercado". O projeto do sistema com uma mola helicoidal não exclui a segunda opção de arame quadrado, mas no presente trabalho a helicoidal se mostrou mais viável, devido à disponibilidade de diversas opções, podendo atender determinadas mudanças no projeto.

Na forma de transmissão de dados o sinal de rádio teve a melhor pontuação, por ser utilizada há mais tempo é bem difundida e mais simples de aplicar, mas em muitos casos está sendo substituída pela Wi-fi.

A tabela escalonada pode ser utilizada em vários processos, mas possui problemas em adaptar os dados arrecadados e pouca praticidade em mostrar os resultados de forma simples e prática. O software teve a maior pontuação devido a sua praticidade, mas o uso de tabela ainda pode ser utilizado para obter algum dado específico. 
Com a tabela montada e as soluções avaliadas conforme conhecimento do projetista, o resultado pode ser expresso como uma linha de combinação conforme a Figura 19, onde estão demonstradas as funções e soluções com os melhores resultados para cumprir a função global.

Figura 19 - Solução de melhor resultado

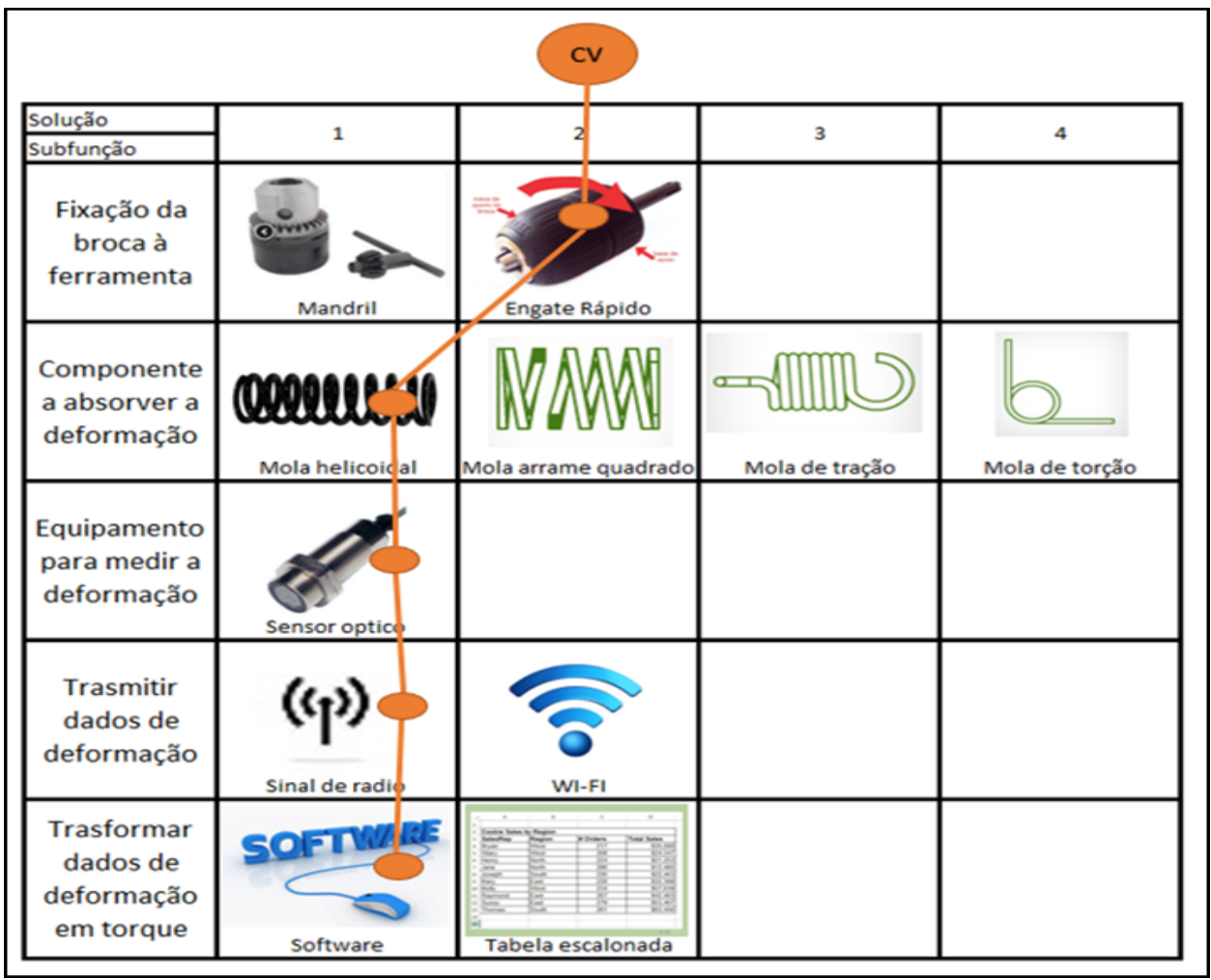

Fonte: O autor (2016).

As decisões tomadas para este projeto vão guiar o projetista. As melhores alternativas foram escolhidas levando em consideração os requisitos para funcionamento do equipamento, mas algumas escolhas podem, em algum novo projeto ou função depois do projeto, serem alteradas, possibilitando adaptá-lo para outras cargas ou alterações de funcionamento.

Mas essas alterações devem ser avaliadas antes de executadas.

O primeiro esboço criado apresenta algumas ideias de funcionamento, onde uma mola realiza transmissão de força de um eixo para o outro, e através da deformação desta mola, é desejado medir o torque, devido ao fato que em um eixo a broca estará fixada e durante o processo de furação criará resistência à rotação gerando os esforços sobre a mola.

Norton (2010) afirma que um importante passo para o projeto é a criação de um esboço da ideia bruta, sem acabamentos e detalhes, apenas para entender o funcionamento básico do equipamento para posteriormente realizar o desenvolvimento do modelo.

Usando as ideias dos esboços à mão livre, um esboço da ideia bruta foi modelado no software SolidWorks, para melhor compreensão do funcionamento, conforme Figura 20. 
Figura 20 - Esboço do modelo

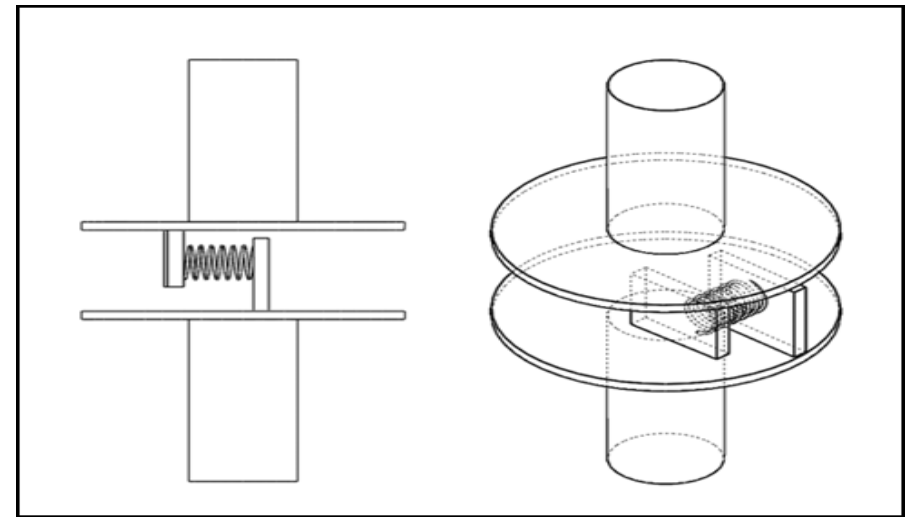

Fonte: O autor (2016).

Com as devidas soluções encontradas no capítulo anterior o primeiro passo é apresentar o modelo desenvolvido com as características necessárias para atender as necessidades propostas, utilizando o software Solidworks para a modelagem das peças e montagem. Na Figura 21 pode-se visualizar externamente o projeto modelado.

Figura 21 - Visão externa do dispositivo

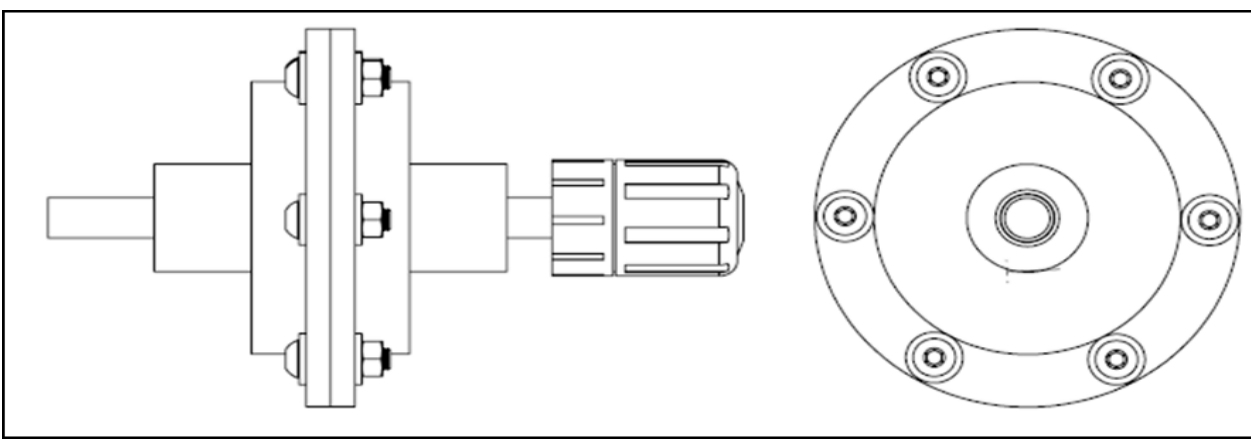

Fonte: $O$ autor (2016).

No interior do projeto a ideia dada no início da metodologia foi mantida, usando uma mola para analisar de forma macroscópica a deformação causada pela resistência do material usinado durante o processo de furação, resolvendo o problema desde tipo de mecanismo que geralmente exigia eixos muito longos, mas também tinham limitações de distâncias graças aos sensores ópticos, retirando o problema mecânico, uma distância mais curta pode ser usada para medir essa deformação.

$\mathrm{Na}$ figura 22 pode-se observar que o mecanismo foi alterado, a mola (componente 1) deve agora ser montada em um único disco. Ao sofrer resistência ao movimento transmitido pelo pino limitador (componente 2), o esforço deve ser passado para mola, que será comprimida, para isso, uma guia (componente 3 ) foi projetado, para evitar o atrito de aço com aço, o material utilizado na guia será o nylon, facilitando o movimento. Se necessária calibragem a mola, o mesmo pode ser feito com o aperto de um parafuso (componente 4). 
Figura 22 - Regulagem e posicionamento da mola

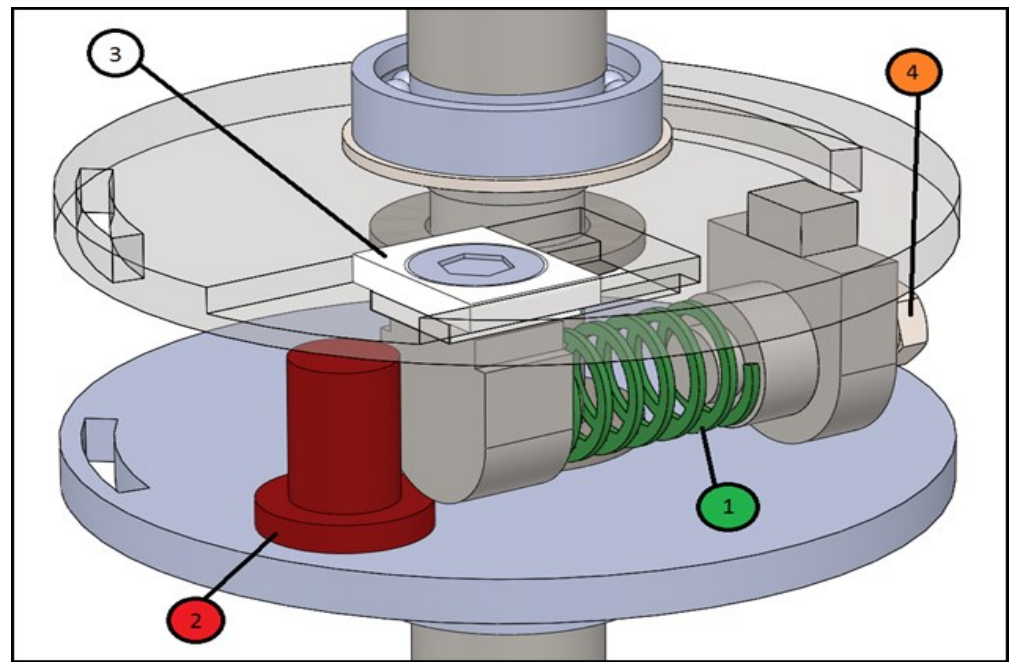

Fonte: O autor (2016).

Dessa forma teremos:

$$
\begin{gathered}
T=F \times \rho \\
F=\frac{\mathrm{T}}{\rho} \\
F=\frac{10 \mathrm{Nm}}{0,03 \mathrm{~m}} \\
F=333,33 \mathrm{~N}
\end{gathered}
$$

A força encontrada é aplicada de forma radial, logo a mesma deve ser decomposta no sentido de trabalho.

$$
\begin{gathered}
\operatorname{sen} 24,76^{\circ}=\frac{\mathrm{F}_{\text {trab }}}{333,33 N} \\
\mathrm{~F}_{\text {trab }}=139,62 \mathrm{~N}
\end{gathered}
$$

Considerando que o percurso projetado no equipamento é para uma mola de 25 milímetros, mas somente $40 \%$ da mesma devem ser deformadas durante o processo normal do equipamento, garantindo assim uma alta vida útil para mola, mantendo longe da deformação plástica. Utilizando a força decomposta no sentido de trabalho e o comprimento a ser deformado da mola, o coeficiente $\mathrm{k}$ da mola pode ser calculado.

$$
\begin{gathered}
k=\frac{\mathrm{F}}{\Delta \mathrm{x}} \\
k=\frac{139,62 \mathrm{~N}}{25 \mathrm{~mm} \times 0,4} \\
k=13,962 \mathrm{~N} / \mathrm{mm}
\end{gathered}
$$


Uma mola deve ser selecionada em uma tabela, levando em consideração as definições calculadas e requisitos de projeto, conforme Figura 23.

Figura 23 - Definição da mola pela tabela

\begin{tabular}{|c|c|c|c|c|c|c|c|c|c|c|c|c|c|}
\hline \multirow[t]{2}{*}{$\mathrm{DH}_{\mathrm{H}}$} & \multirow[t]{2}{*}{$D_{d}$} & \multirow[t]{2}{*}{$d$} & \multirow[t]{2}{*}{$\begin{array}{l}b_{0} \\
\mathrm{~mm}\end{array}$} & \multirow[t]{2}{*}{ Reteréncia } & \multirow{2}{*}{$\begin{array}{l}\text { Rigidez } \\
\mathrm{N} / \mathrm{mm}\end{array}$} & \multicolumn{2}{|c|}{$25 \%$} & \multicolumn{2}{|c|}{ 多 } & \multicolumn{2}{|l|}{ 酋 } & ! & $\begin{array}{c}\text { D } \\
\text { Aprox. }\end{array}$ \\
\hline & & & & & & $\mathrm{mm}$ & $\mathrm{N}$ & $\mathrm{mm}$ & $N$ & mm & $\mathrm{N}$ & mm & $\mathrm{N}$ \\
\hline \multirow{10}{*}{16} & \multirow{10}{*}{8} & \multirow{10}{*}{2} & 25 & TV 16.25 & 17.9 & 6.3 & 112 & 7.5 & 134 & 10.0 & 179 & 14.7 & 262 \\
\hline & & & 32 & IV16.32 & 13.5 & 8.0 & 108 & 9.6 & $129^{\circ}$ & 12.8 & 173 & 18.5 & $249^{\circ}$ \\
\hline & & & 38 & TV $16 \cdot 38$ & 10.5 & 9.5 & 100 & 11.4 & 120 & 15.2 & 160 & 22.4 & 236 \\
\hline & & & 4 & TV 16.44 & 8.8 & 11.0 & 96 & 13.2 & 116 & 17.6 & 154 & 25.9 & 227 \\
\hline & & & 51 & TV16.51 & 7.6 & 12.8 & 97 & 15.3 & 116 & 20.4 & 155 & 30.0 & 227 \\
\hline & & & 64 & TV 16.64 & 5.9 & 16.0 & 95 & 19.2 & 114 & 25.6 & 152 & 37.8 & 222 \\
\hline & & & 76 & TV 16.76 & 4.8 & 19.0 & 91 & 22.8 & 109 & 30.4 & 145 & 45.2 & 218 \\
\hline & & & 89 & TV16.89 & 4.0 & 22.3 & 90 & 26.7 & 108 & 35.6 & 144 & 52.8 & 214 \\
\hline & & & 102 & TV $16 \cdot 102$ & 3.5 & 25.5 & 90 & 30.6 & 108 & 40.8 & 144 & 60.7 & 214 \\
\hline & & & 305 & IN $16 \cdot 305$ & 1.1 & 76.3 & 85 & 91.5 & 103 & 122.0 & 137 & 183.9 & 205 \\
\hline
\end{tabular}

Fonte: Polimold (2016).

A mola selecionada tem um o comprimento igual à definição do projeto, mas coeficiente $\mathrm{k}$ maior, durante a compressão da mola a força de compressão sobre ela aumenta, devido ao ângulo entre o vetor de força resultante e o vetor de força no sentido de trabalho ficar cada vez menor. A força aplicada sobre a mola quando seu curso está quase completo chega a ficar duas vezes maior do que a inicial, como pode ser visto na Figura 24 a representação do aumento do ângulo do vetor e tamanho do próprio vetor, além da redução do ângulo entre o vetor radial e o vetor do sentido de trabalho.

Figura 24 - Decomposição da força atuante sobre a mola

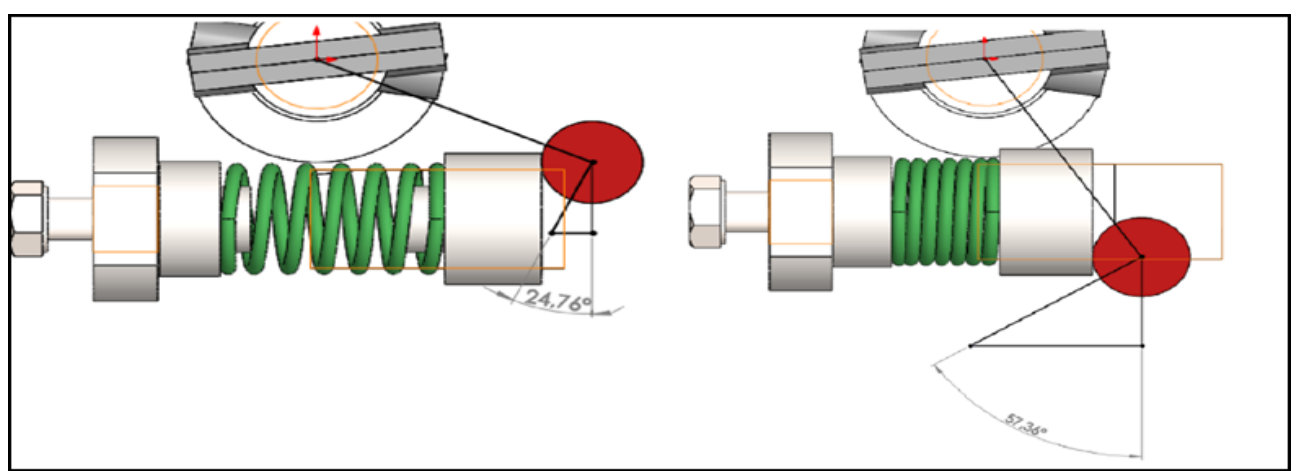

Fonte: O autor (2016).

A deformação da mola será a referência para descobrir o torque utilizado durante a furação, mas como a visualização dessa deformação é indisponível, serão utilizados sensores ópticos para definir o ângulo de torção dos discos internos do dispositivo, através de fendas capazes de deixar passar certa quantia de luz, dentro um determinado ângulo, quando a mola não está sofrendo esforço, está totalmente aberto e a fenda está com seu ângulo completo, quanto maior a deformação da mola, na mesma escala, será menor o ângulo de luz recebido no receptor óptico. Na Figura 25 podem-se ver os discos com as fendas de passagem 
de luz, as fendas de mesmo tamanho e localizadas na parte inferior da imagem. Para a medição não ter problema graças à variação de velocidade durante a furação, outra fenda foi aberta na parte superior, esta deve manter sempre o mesmo tamanho de feixe de luz, então o rasgo no disco superior (A) segue o mesmo caminho, mas é prolongado, para o deslocamento do disco não obstruir a passagem de luz por esta fenda e assim possibilitar a medição da rotação do equipamento.

Figura 25 - Discos superior (A) e inferior (B)

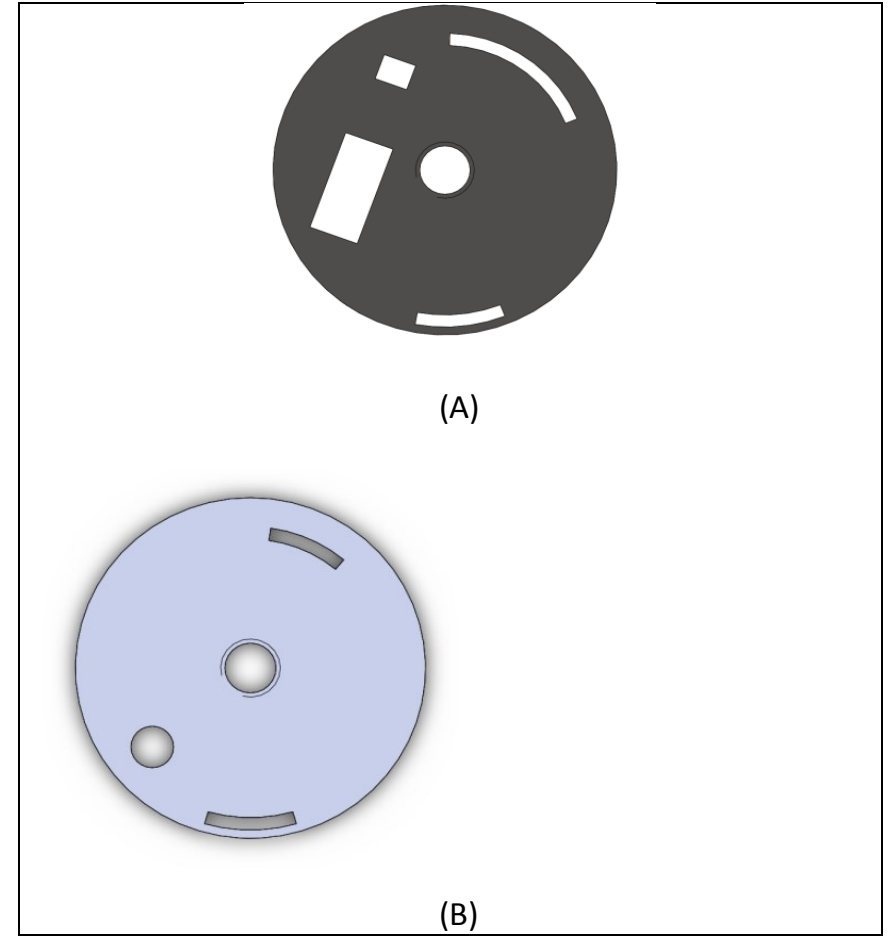

Fonte: O autor (2016).

Para garantir o funcionamento do equipamento, o movimento do eixo não pode ser passado para a carcaça, considerando que o emissor e o receptor ópticos vão ser posicionados na carcaça, desta forma a medição da deformação seria impossível, deixando o feixe de luz permanentemente aberto ou fechado. Para separar o movimento do eixo e da carcaça, quatro rolamentos foram posicionados no equipamento, dois na parte superior e dois na inferior. Garantindo que os eixos, inferior e superior, não movimente a carcaça, também garantindo que a única forma de transmissão de um eixo para o outro seja através da mola. Para garantir a fixação dos rolamentos, dois tamanhos de rolamentos foram utilizados, mantendo sempre apoios para os rolamentos e montados com ajuste. Para fixação do rolamento de maior diâmetro será utilizado um anel elástico, conforme Figura 26. Para evitar entrada de poeira, fluidos ou outros agentes que possam vir a danificar o equipamento, retentores serão posicionados na entrada e saída do mesmo. 
Figura 26 - Corte demonstrando posicionamento dos rolamentos

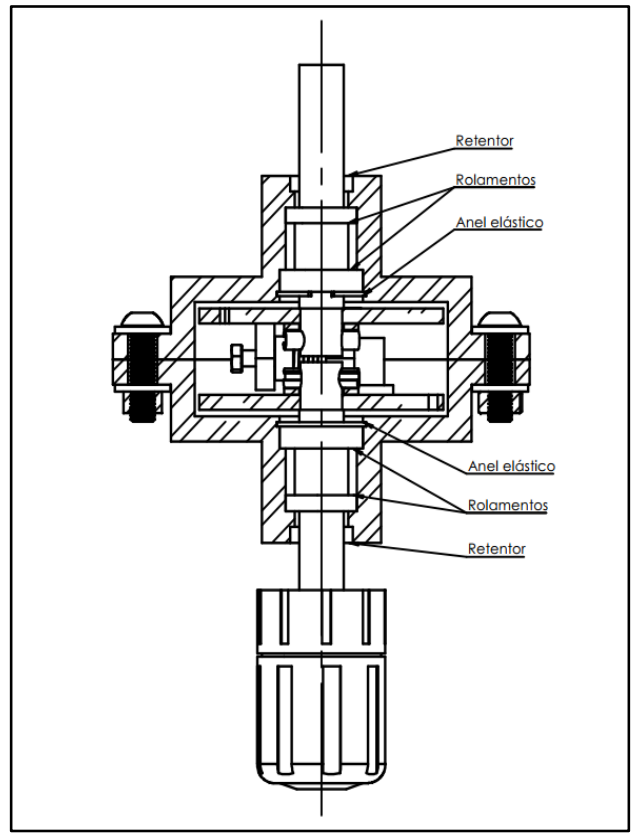

Fonte: O autor (2016).

Conforme solicitado no início do projeto, a montagem, desmontagem e manutenção podem ser feitos manualmente, todos os processos que impedissem estas solicitações foram retirados do projeto, não tendo solda ou outros processos que dificultariam a montagem ou desmontagem, garantindo praticidade e velocidade. Como pode ser visto na Figura 27 a montagem do equipamento não tem complicações e será feita totalmente manual. Para conseguir o objetivo de montagem o eixo superior, que é ligado no eixo árvore, deve conter uma rosca esquerda, pois durante o processo de furação o torque aplicado sobre ele desmontaria parte do sistema. Para garantir que nenhum esforço não previsto cause o mesmo problema, pinos elásticos são posicionados acima do disco, impedindo seu movimento axial.

Figura 27 - Representação de montagem do equipamento

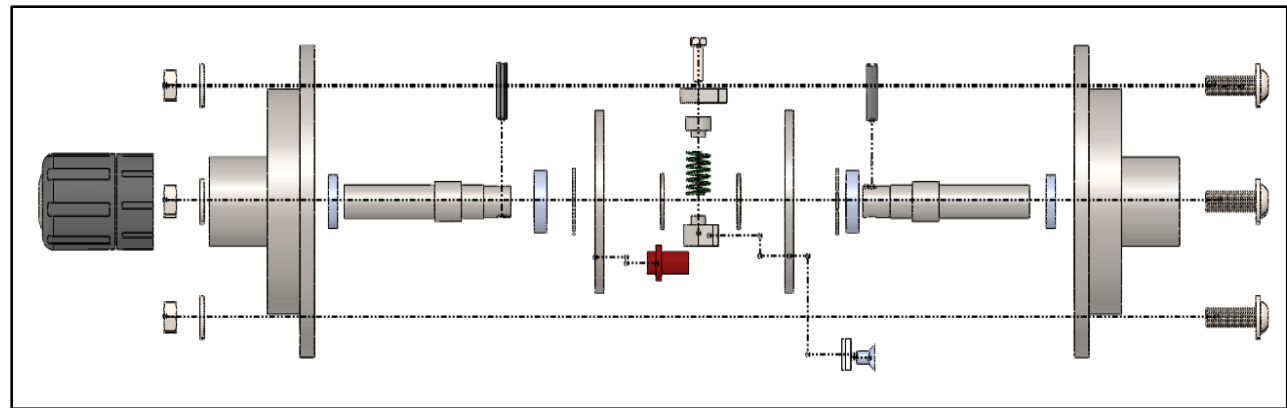

Fonte: O autor (2016).

\section{RESULTADOS}

Os requisitos exigidos e desejados vistos no início do projeto são comparados com o projeto concluído, possibilitando analisá-los. Conforme Quadro 5. 
Quadro 5-Comparando parâmetros mestres com os do projeto

\begin{tabular}{|c|c|c|c|c|}
\hline $\begin{array}{c}\text { Característica } \\
\text { Principal }\end{array}$ & $\begin{array}{c}\text { Características } \\
\text { Principal }\end{array}$ & $\begin{array}{l}\text { Desejada/ } \\
\text { Exigida }\end{array}$ & Requisito & $\begin{array}{l}\text { Parâmetros de } \\
\text { projeto }\end{array}$ \\
\hline \multirow{3}{*}{ Geometria } & Altura & $E$ & $\begin{array}{c}\text { Máximo } 250 \\
\text { mm }\end{array}$ & 186 mm \\
\hline & $\begin{array}{l}\text { Diâmetro } \\
\text { (carcaça) }\end{array}$ & $E$ & $\begin{array}{c}\text { Máximo } 200 \\
\mathrm{~mm}\end{array}$ & $140 \mathrm{~mm}$ \\
\hline & Diâmetro (eixo) & $\mathrm{D}$ & $15 \mathrm{~mm}$ & $15 \mathrm{~mm}$ \\
\hline Forças & $\begin{array}{l}\text { Torque } \\
\text { máximo }\end{array}$ & D & 10 N.m & 10 N.m \\
\hline \multirow{5}{*}{ Material } & Eixo & $\mathrm{D}$ & $\begin{array}{l}\text { Material } \\
\text { disponível }\end{array}$ & $\begin{array}{c}\text { Aço } 1020 \\
\text { (disponível) }\end{array}$ \\
\hline & Carcaça & D & $\begin{array}{c}\text { Material } \\
\text { disponível }\end{array}$ & $\begin{array}{c}\text { Aço } 1020 \\
\text { (disponível) }\end{array}$ \\
\hline & Mola & D & Aço Mola & Aço Mola \\
\hline & Guia deslizante & $\mathrm{D}$ & Nylon & Nylon \\
\hline & $\begin{array}{c}\text { Outros } \\
\text { componentes }\end{array}$ & D & $\begin{array}{l}\text { Aço } 1020 \text { ou } \\
\text { terceirizado }\end{array}$ & $\begin{array}{l}\text { Aço } 1020 \text { ou } \\
\text { terceirizado }\end{array}$ \\
\hline Sinal & $\begin{array}{c}\text { Leitor de } \\
\text { posição }\end{array}$ & $\mathrm{D}$ & Óptico & Óptico \\
\hline \multirow[t]{3}{*}{ Produção } & Usinagem & D & Eixo, Carcaça & $\begin{array}{c}\text { Todas as peças, } \\
\text { exceto discos e } \\
\text { componentes } \\
\text { de fixação. }\end{array}$ \\
\hline & Montagem & $\mathrm{E}$ & Manual & Manual \\
\hline & Manutenção & $E$ & Manual & Manual \\
\hline
\end{tabular}

Fonte: O autor (2016).

A disponibilidade de matéria prima e processos de usinagem do núcleo de Engenharia Mecânica da Universidade de Passo Fundo possibilitaram a fabricação de mais peças que o esperado, algumas peças e processos do projeto foram modificados para aproveitar o máximo possível de materiais disponíveis.

Após a etapa de projeto e análise a construção do protótipo foi iniciada, começando a construção das peças conforme projeto. Aproveitando os materiais disponíveis o material selecionado para a maioria dos componentes foi o Aço SAE 1020, sempre que a seleção deste material não prejudicasse a função do componente.

A grande maioria dos componentes foi produzida no núcleo de Engenharia Mecânica da Universidade de Passo Fundo, apenas dois componentes tiveram necessidade de serem terceirizados, que foram os dois discos que necessitaram ser cortados no laser. Pode-se ver no Quadro 6 os desenhos dos componentes usinados. 
Quadro 6-Desenhos dos componentes usinados

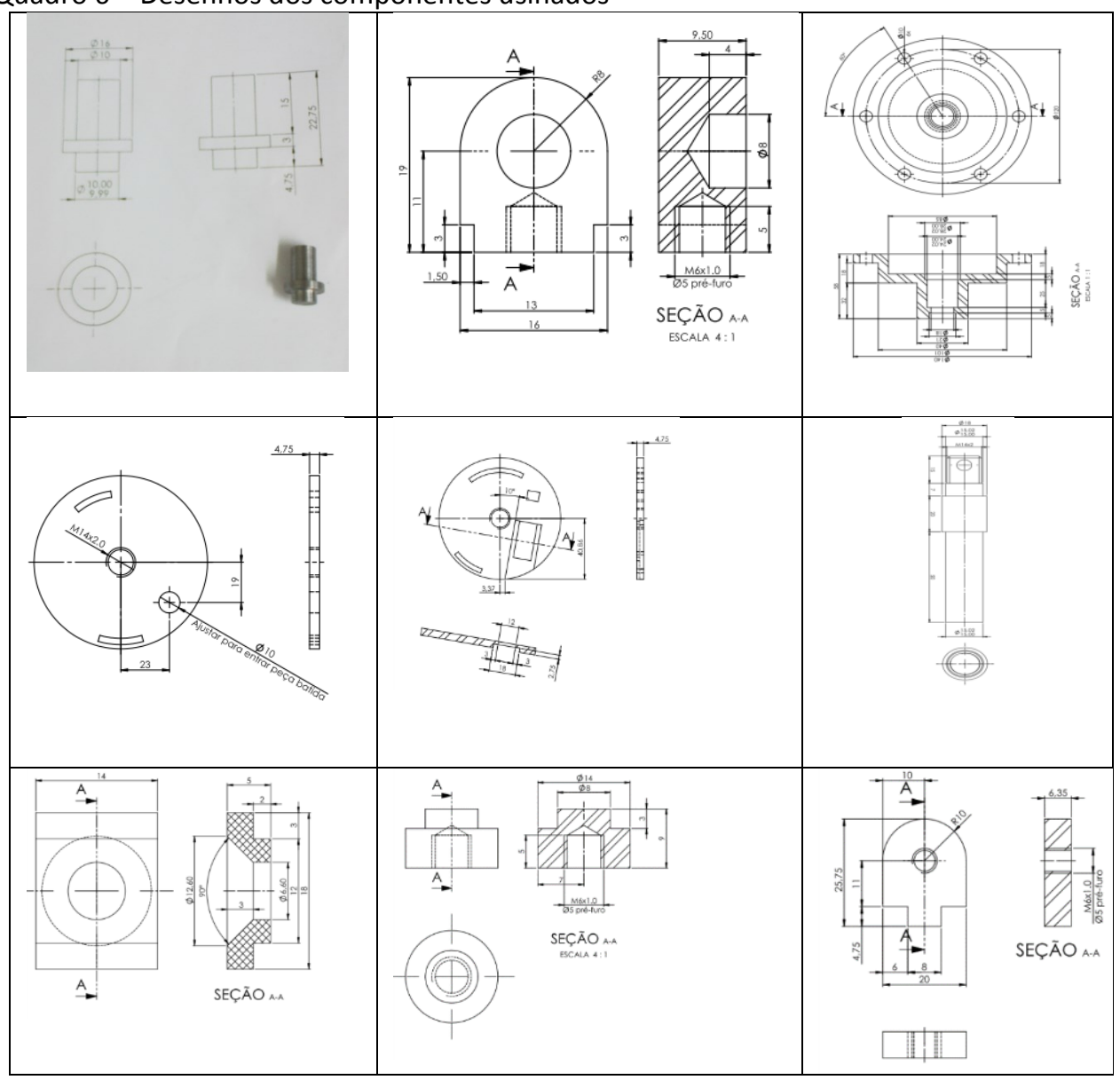

Fonte: O autor (2016).

Os discos tiveram somente dois processos de usinagem realizados dentro do Campus, o restante dos componentes presentes nos desenhos do Quadro 6 foi totalmente produzido dentro do Núcleo de Engenharia Mecânica da Universidade de Passo Fundo.

Após a fabricação de cada componente foi iniciado a montagem do protótipo como pode ser visto na Figura 28 onde foi realizada a montagem do conjunto superior do projeto.

Figura 28 - Montagem do conjunto superior

Fonte: $\mathrm{O}$ autor (2016).

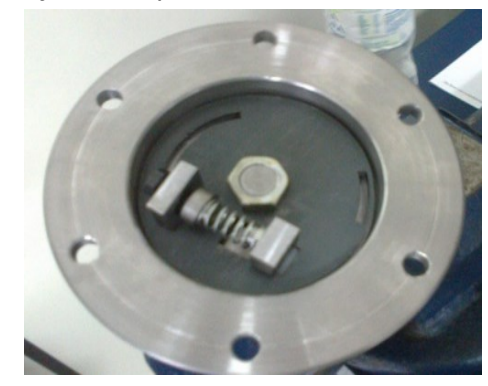

Durante a fabricação do protótipo, as fabricações de algumas peças se mostraram inviáveis, pois a operação de rosca esquerda não poderia ser feita por falta de ferramenta, além de não ter um gabarito para conferir a rosca esquerda 
do eixo, a solução foi produzir os dois eixos com roscas direitas, utilizando uma contra-porca para impedir o movimento axial dos discos.

Conforme Figura 29 pode-se ver a montagem dos equipamentos do conjunto inferior.

Figura 29 - Montagem do conjunto inferior

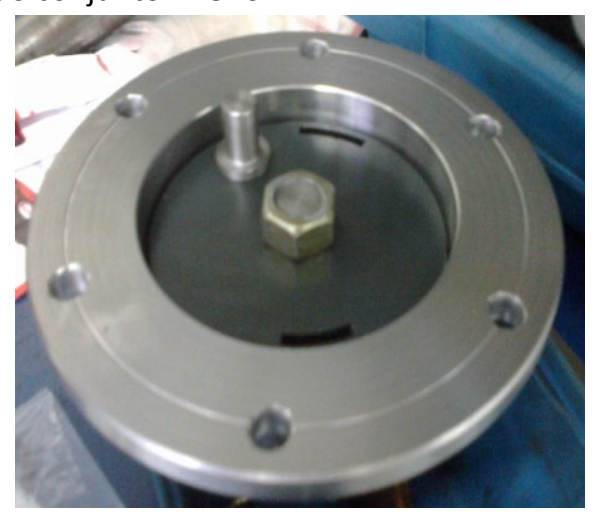

Fonte: O autor (2016).

Após a montagem do conjunto superior e inferior, os conjuntos são unidos e fixados. Retentores são posicionados nas aberturas de passagem do eixo, para evitar entrada de qualquer substância distinta ao sistema. Conforme Figura 30.

Figura 30 - Montagem do protótipo

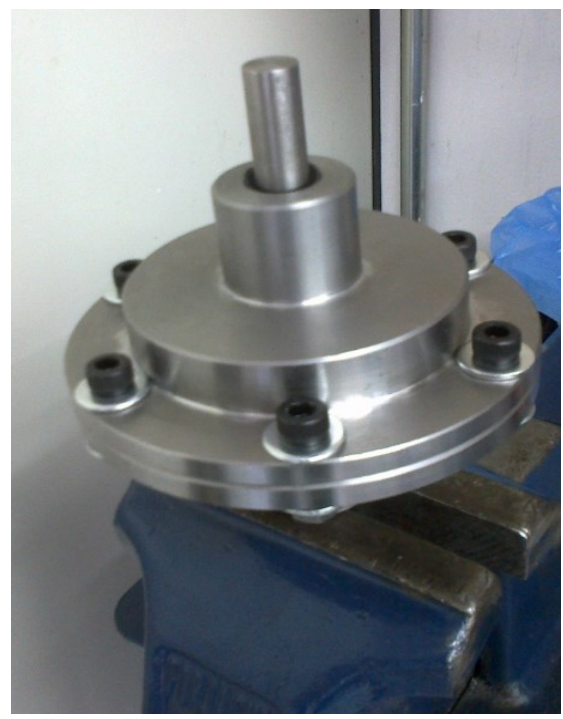

Fonte: O autor (2016).

Na Figura 30 a montagem está quase completa, faltando o engate rápido que será posicionado no eixo inferior e o suporte para montagem na máquina, concluindo a parte mecânica que pode ser construída de forma independente de outros componentes.

Para instalação da parte elétrica do equipamento, furos devem ser feitos na carcaça, tanto para emissor de luz como para o receptor. Os receptores e emissores devem estar perfeitamente alinhados entre si e também com os rasgos 
realizados nos discos para passagem de luz, por esta razão essa furação será realizada junto com a instalação do equipamento eletrônico.

\section{DISCUSSÃO DOS RESULTADOS}

De acordo com os resultados expostos no capítulo anterior, pode se perceber que a construção de um dinamômetro no centro de tecnologia mecânica se mostrou muito oportuno, sendo que a construção do mesmo se mostrou um projeto complexo e de baixo custo.

Para que se houvessem resultados comprovatórios sobre o desempenho do dispositivo, o mesmo teve de ser averiguado e testado em uma bancada de teste conforme demonstra a Figura 31.

Figura 31 - Dispositivo acoplado no motor e bancada WEG para ensaio de motores

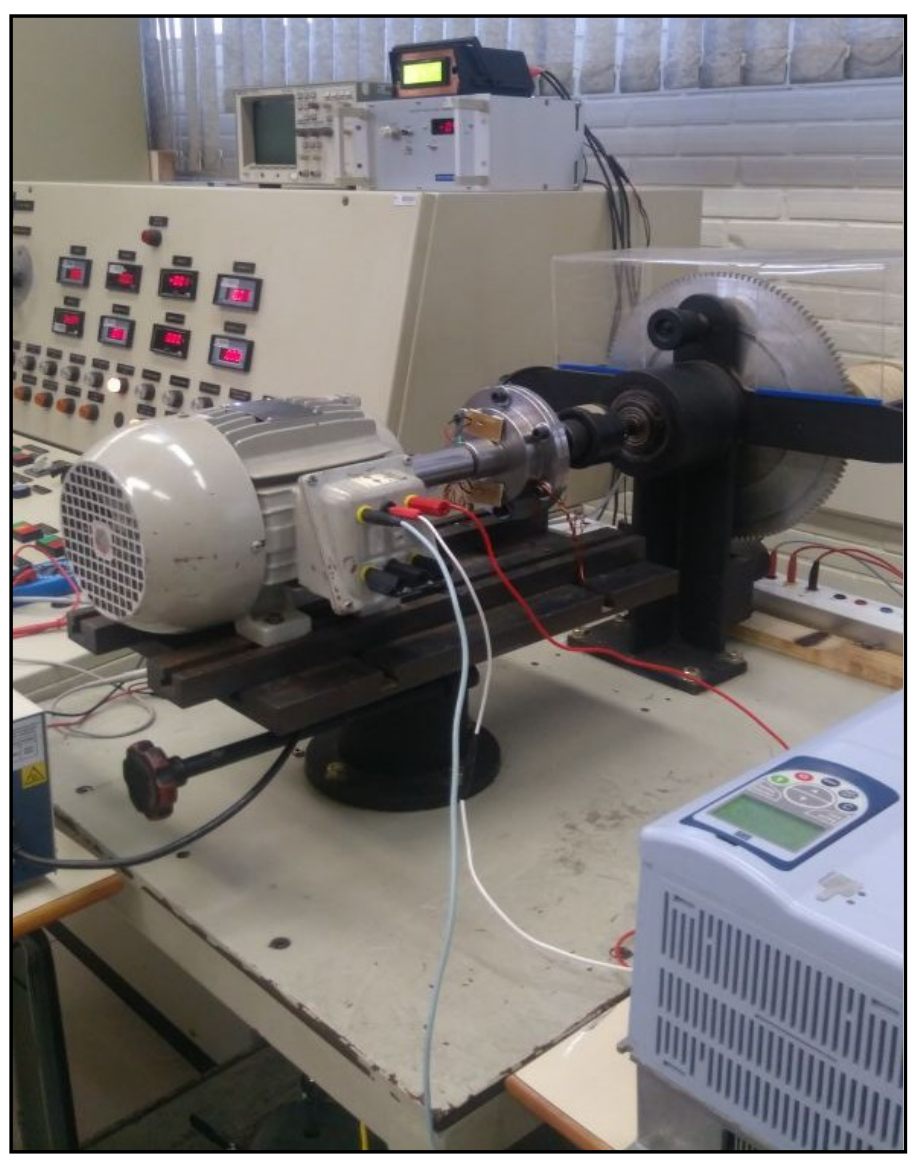

Fonte: O autor (2017).

Para realizar o ensaio do sensor de RPM, foi utilizado um motor com velocidade em vazio de 1800 RPM.

O dispositivo foi testado inicialmente, com mola azul (TB), uma vez que esta é indicada para cargas médias e possui deflexão máxima de até $37,5 \%$, porém a mesma não atendeu a necessidade do projeto, realizando leitura de no máximo $5.3 \mathrm{Nm}$ ao ser submetido à velocidade máxima do motor usado no ensaio, quando deveria realizar uma leitura de $10 \mathrm{Nm}$. 
Refazendo os cálculos anteriores sem a decomposição de forças considerando que toda a força gerada é utilizada para comprimir a mola temos:

$$
\begin{gathered}
k=\frac{\mathrm{F}}{\mathrm{x}} \\
k=\frac{333,33 \mathrm{~N}}{25 \mathrm{~mm} \times 0,2} \\
k=66,66 \mathrm{~N} / \mathrm{mm}
\end{gathered}
$$

Desta forma foi necessária a escolha de uma mola vermelha (TR), conforme demonstra a Figura 32 que é indicada para cargas pesadas, que mantivesse as mesmas dimensões principais Lo, Dd e Dh.

Com a colocação desta nova mola foi possível atender a solicitação de $10 \mathrm{Nm}$, como demonstra Figura 32 gerada na bancada de testes abaixo.

Figura 32 - Dados fornecidos pela bancada de teste pelo software Agilent

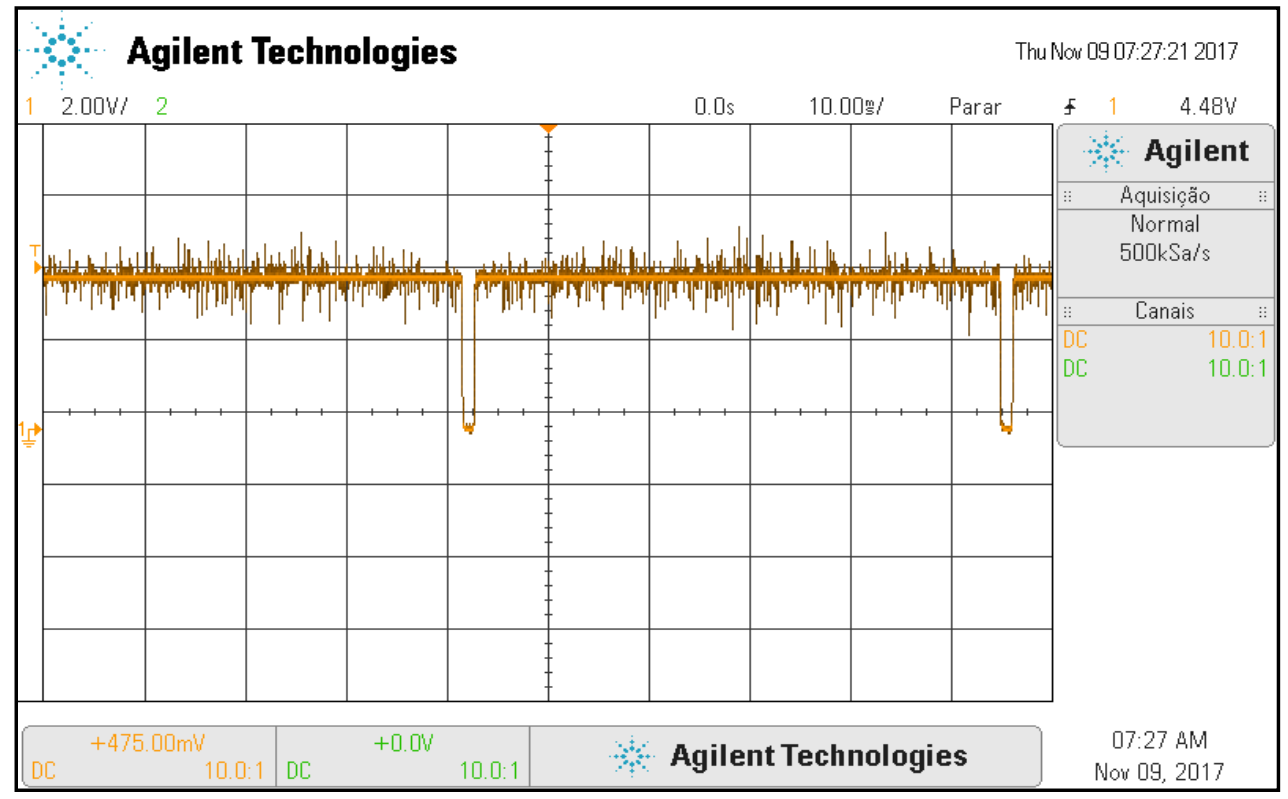

Fonte: O autor (2017).

Com a construção do equipamento feita dentro da Universidade de Passo Fundo, os preços deste equipamento foram calculados com base nos preços do mercado e estimando os preços como terceirização de serviço, aumentando o custo de fabricação real. O mandril terá o custo de $\mathrm{R} \$ 30,00$.

Somente os componentes já presentes no equipamento estão considerados na Figura 33. 
Figura 33 - Custos de fabricação

\begin{tabular}{|c|c|c|c|c|}
\hline \multicolumn{5}{|c|}{ Custos de construção do protótipo } \\
\hline \multirow{2}{*}{$\begin{array}{l}\text { Operação } \\
\text { Torno }\end{array}$} & Tempo (h) & Preço/hora & \multicolumn{2}{|l|}{ Total } \\
\hline & 9 & 65,00 & $\mathrm{R} \$$ & 585,00 \\
\hline Fresa & 3 & 75,00 & $\mathrm{R} \$$ & 225,00 \\
\hline Bancada & 3 & 45,00 & $\mathrm{R} \$$ & 135,00 \\
\hline Material & Peso (kg) & Valor/kg (médio) & \multicolumn{2}{|l|}{ Total } \\
\hline Aço 1020 & 3,027 & 3,50 & $\mathrm{R} \$$ & 10,59 \\
\hline Componentes terceirizados & Preço (uni) & Quantidade & \multicolumn{2}{|l|}{ Total } \\
\hline Discos (laser) & $R \$ \quad 26,41$ & 2 & $\mathrm{R} \$$ & 52,82 \\
\hline Rolamentos $(15 \times 24 \times 5)$ & $\mathrm{R} \$ 35,00$ & 2 & $\mathrm{R} \$$ & 70,00 \\
\hline Rolamentos $(15 \times 28 \times 7)$ & $\mathrm{R} \$ 48,00$ & 2 & $\mathrm{R} \$$ & 96,00 \\
\hline Parafusos Allen M8 & $\mathrm{R} \$ \quad 1,60$ & 6 & $\mathrm{R} \$$ & 9,60 \\
\hline Parafusos Allen M6 & 1,00 & 2 & $\mathrm{R} \$$ & 2,00 \\
\hline Arruelas (M8) & 0,20 & 12 & $\mathrm{R} \$$ & 2,40 \\
\hline Porcas (M8) & 0,60 & 6 & $\mathrm{R} \$$ & 3,60 \\
\hline Porcas (14) & 2,00 & 2 & $\mathrm{R} \$$ & 4,00 \\
\hline & & Preço final & $\mathrm{R} \$ 1$ & $.196,01$ \\
\hline
\end{tabular}

Fonte: O autor (2016).

Os componentes eletrônicos e a mão de obra que seria gasta para desenvolver o equipamento, estão estimados em $R \$ 1.940,00$, totalizando em $R \$ 3.166,01$ como o custo total de fabricação do dinamômetro.

O custo total do equipamento está em torno de $\mathrm{R} \$ 3.166,01$, quando comparado com o equipamento no mercado que está em torno de $\mathrm{R} \$ 6.227,00$, pode-se ver uma redução de aproximadamente $49,16 \%$ do valor inicial. Os custos do protótipo foram extremamente baixos em comparação com os encontrados no mercado, conforme mostrado, confirmando a viabilidade do equipamento.

\section{CONCLUSÃO}

A existência de mão-de-obra especializada, máquinas-ferramentas e material, propicia um quadro favorável à construção do equipamento na Universidade. Pode se perceber que a confeç̧ão de um equipamento nas dependências da Universidade de Passo Fundo, para uso em seus laboratórios foi viável, mediante a expressiva quantia de dinheiro economizada quando comparado com equipamento similar já manufaturado.

Portanto, Obteve se como resultado um dispositivo barato, fabricado com materiais já existentes no laboratório e capaz de realizar satisfatoriamente o mensuramento do torque dinâmico de um eixo rotativo de uma determinada máquina.

Contudo, as incertezas presentes nesse equipamento geram temas e propostas para trabalhos futuros, podendo seguir várias linhas de pesquisa, dentre a principal que pode ser destacada é a calibração do dispositivo.

Seguindo a ideologia dos objetivos específicos, ficou evidente que próximas etapas poderão ser desenvolvidas em futuros trabalhos. 
a. Avaliar o estado da arte sobre dispositivos;

No início do projeto um estudo sobre dinamômetros foi realizado, nesta etapa possíveis soluções existentes foram apresentadas e proporcionaram aprofundamento no assunto, possibilitando o desenvolvimento de novas ideias para solucionar o problema.

b. Implementar técnicas de projeto conceitual;

Após os estudos de caso, técnicas de projeto conceitual foram estudadas e implantadas, com base em Löbach o projeto foi estruturado, porém também foram utilizadas técnicas de outros autores, em momentos que se mostraram oportunas.

c. Padronização da Mola;

Após as alterações do projeto, a escolha da mola para o dispositivo foi refeita. Desta forma, foi possível atender aos requisitos mínimos propostos no inicio do trabalho.

d. Validação do Dispositivo;

Com a sensorização do equipamento realizado pelos acadêmicos do curso de Engenharia Elétrica da UPF, foi possível validar o dispositivo por meio de testes em uma bancada WEG para ensaio de motores.

Como projeto futuro, o acoplamento entre o dispositivo e a broca de furação pode ser realizado, além também a realização de testes no centro de usinagem vertical V-400. Melhorias ou adaptações no projeto também podem ser realizadas.

Os eventuais erros que o equipamento possa apresentar são perfeitamente compreensivos e praticamente imperceptíveis, pois como seu uso será somente para fins didáticos serve inclusive para que os acadêmicos que utilizarão esse dispositivo possam identifica-los e futuramente corrigi-los. 


\title{
Design and construction of a Dynamometer to measure the dynamic torque of a rotary axis
}

\begin{abstract}
This document consists of developing the design and construction of a dynamometer to be coupled to the shaft of a vertical machining center. The dynamometer to be developed must be able to monitor process parameters, aiming the measurement of dynamic torque. For the operation of the dynamometer, a deformation must be analyzed. In this case, the deformation is given by a calibrated spring. Its deformation and variations in rotational speed will be captured by infrared sensors and, as it uses a non-contact method in measurement and transmission, it becomes less sensitive to vibrations. Maintaining good clamping and avoiding vibrations are important factors within the design, so the study of bearings, adjustments and tolerances becomes necessary. Another important factor to consider is the specific materials of each component, in order to avoid overweight and lower the cost, without compromising the acquisition of data. With the respective project, it is intended to meet a need of the laboratory of measurement of efforts, in addition to the technical knowledge that will be acquired, both mechanically and electronically, during its development, acquisition and interpretation of information.
\end{abstract}

KEYWORDS: Dynamometers. Dynamic torque. Rotary torque. 


\section{REFERÊNCIAS}

BALBINOT, A.; BRUSAMARELLO V. J. Instrumentação e Fundamentação de Medidas. 2ㅇe ed. Arte e Ideia. Rio de Janeiro, 2007.

BORGES, A. N. Caracterização de escovas de grafite e avaliação do seu desempenho em função da microestrutura. Dissertação de Mestrado: Universidade Federal do Rio Grande do Norte. Pós-Graduação em Engenharia Mecânica. Natal - RN, 2007.

BORGES, J. C. S.; LIMA FILHO, A. C.; BELO, F. A. Sensor Hall effect on analyses Mechanical Stress. Journal of Mechanics Engineering and Automation. v.5, p.1925, 2015. ISSN: 2159-5275. doi: 10.17265/2159-5275/2015.01.003. crossref

BRITO, R. M. Sistema eletro-eletrônico para medição direta de torque em dispositivos girantes utilizando extensômetros de resistência elétrica. 1994. 165 f. Tese (Doutorado em Engenharia Metalúrgica e dos Materiais) - Universidade Federal do Rio Grande do Sul, Porto Alegre, RS, 1994.

BRUNETTI, F. Motores de Combustão Interna. Vol $1.3^{\circ}$ ed. São Paulo: Blucher, 2012.

CHEONG, Y. D.; KIM, J. W.; OH, S. H.; LEE, C. W.; 1999, “Analysis and Development of the Angular Twist Type Torque-meter", Composite Structures, Vol. 47, pp. 457-462.

DEVITTE, W. Desenvolvimento de um Sistema para medir o conjugado de um motor de indução. Trabalho de conclusão de curso, Engenharia de Controle e Automação. UNIVATES, Lajeado, 2013.

EBAY Acesso: http://www.ebay.com/bhp/torque-sensor. Página acessada em: 03 de outubro de 2016.

FIGLIOLA, R.; BEASLEY, D.; 2011, Theory and design for the mechanical measurements, $5^{\text {th }}$ ed. Portand: John Wiley \& Sons, 605 p. Danvers, USA, 2011. ISBN: 978-0470547410.

FRADEN, J. Handbook of Modern Sensors. Physics, Designs and Aplications. 3 ed, Springer - Verlag New York, Inc., 2004. ISBN 0-387-00750-4.

GIL, A. C. Como elaborar projetos de pesquisa. 4. ed. São Paulo: Atlas, 2007. 
GRANTE, Apostila de Extensometria Acesso:

http://grante.ufsc.br/download/Extensometria/SG-Apostila.pdf, Grupo de

Análise e Projeto Mecânico, UFSC. Página acessada em: 13 de setembro de 2016.

LIMA FILHO, A. C.; Belo, F. A.; Santos, J. L. S.; Anjos E. G. Self-Powered Telemetric Torque Meter, Journal of Dynamic Systems, Measurement and Control, v. 133, p. 1-7, 2011.

LIMA, T. Ponte de Wheatstone Acesso: http://www.embarcados.com.br/pontede-wheatstone/. Página acessada em: 03 de outubro de 2016.

NASCIMENTO, N.; et al. "Torquímetro para motores ultra-sônicos". In: CONEM 2000. Natal-RN, 2000.

NORTON, R. L.; Cinemática e Dinâmica dos Mecanismos. Porto Alegre: AMGH Ed. LTDA, 2010.

OLIVEIRA, J. S. Avaliação experimental e teórica do torque no laminador de chapas grossas da USIMINAS. Dissertação de Mestrado. Pós-Graduação em Engenharia Metalúrgica e de Minas. UFMG. Belo Horizonte, 2010.

PAHL, G.; BEITZ, W.; FELDHUSEN, J.; GROTE, H. K. Projeto na Engenharia. São Paulo: Edgard Blucher, 2005.

POLIT, D. F.; BECK, C. T.; HUNGLER, B. P. Fundamentos de pesquisa em enfermagem: métodos, avaliação e utilização. Trad. De Ana Thorell. 5. ed. Porto Alegre: Artmed, 2004.

POLIMOLD. Catálogo de molas Acesso:

http://www.polimold.com.br/downloads/molas/molas.pdf. Página acessada em: 01 de novembro de 2016.

VERNON, P. The nature-nurture problem in creativity. Handbook of Creativity, p.93-110. New York: Plenum Publishing Corp. 1989. crossref

WASSERMANN, J.; et al. "Wireless Data Transfer System for Rotating Machinery - Very Robust Against Electromagnetic Interference", 1st International Conference on Sensing Technology, Palmerston North, New Zealand, pp. 651647. Nov 21-23, 2005. 
Recebido: 5 Jun. 2018

Aprovado: 19 Mai. 2019

DOI: 10.3895/gi.v15n2.8381

Como citar:

DE BORTOLI, Oscar. et al. Projeto e Contrução de um Dinamômetro para medir o Torque Dinâmico de um Eixo Rotativo. R. Gest. Industr., Ponta Grossa, v. 15, n. 2, p. 16-52, Abr/Jun 2019. Disponível em: $\leq$ https://periodicos.utfpr.edu.br/rgi . Acesso em: XXX.

Correspondência:

Guilherme Regner Nava

Rua José Reinaldo Angonese, 205, José Bonifácio, Erechim, Rio Grande do Sul, Brasil.

Direito autoral: Este artigo está licenciado sob os termos da Licença Creative Commons-Atribuição 4.0 Internacional.

(c) (1) 